\title{
Synthesis Study on Transitions in Signal Infrastructure and Control Algorithms for Connected and Automated Transportation
}




\section{DOCUMENT AVAILABILITY}

Reports produced after January 1, 1996, are generally available free via US Department of Energy (DOE) SciTech Connect.

Website http://www.osti.gov/scitech/

Reports produced before January 1, 1996, may be purchased by members of the public from the following source:

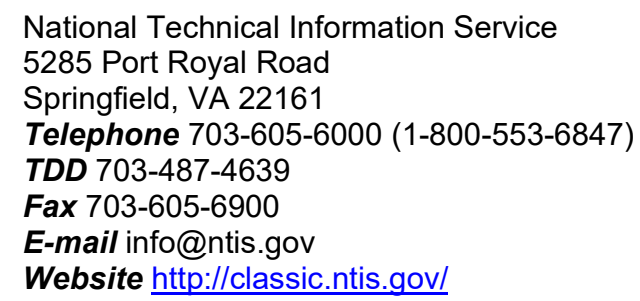

Reports are available to DOE employees, DOE contractors, Energy Technology Data Exchange representatives, and International Nuclear Information System representatives from the following source:

Office of Scientific and Technical Information

PO Box 62

Oak Ridge, TN 37831

Telephone 865-576-8401

Fax 865-576-5728

E-mail reports@osti.gov

Website http://www.osti.gov/contact.html

This report was prepared as an account of work sponsored by an agency of the United States Government. Neither the United States Government nor any agency thereof, nor any of their employees, makes any warranty, express or implied, or assumes any legal liability or responsibility for the accuracy, completeness, or usefulness of any information, apparatus, product, or process disclosed, or represents that its use would not infringe privately owned rights. Reference herein to any specific commercial product, process, or service by trade name, trademark, manufacturer, or otherwise, does not necessarily constitute or imply its endorsement, recommendation, or favoring by the United States Government or any agency thereof. The views and opinions of authors expressed herein do not necessarily state or reflect those of the United States Government or any agency thereof. 
Computational Sciences and Engineering Division

Synthesis Study on Transitions in Signal Infrastructure and Control Algorithms for Connected and Automated Transportation

\author{
H(Husain) M Abdul Aziz \\ Hong Wang \\ Stanley Young \\ Joshua Sperling \\ John M. Beck
}

Date Published:

June 2017

\author{
Prepared by \\ OAK RIDGE NATIONAL LABORATORY \\ Oak Ridge, TN 37831-6283 \\ managed by \\ UT-BATTELLE, LLC \\ for the \\ US DEPARTMENT OF ENERGY \\ under contract DE-AC05-00OR22725
}




\section{List of Acronyms}

$\begin{array}{ll}\text { CAV } & \text { Connected and Automated Vehicle } \\ \text { CV } & \text { Connected Vehicle } \\ \text { V2V } & \text { Vehicle-to-Vehicle } \\ \text { V2I } & \text { Vehicle-to-Infrastructure } \\ \text { I2I } & \text { Infrastructure-to-Infrastructure } \\ \text { SPaT } & \text { Signal Phase and Timing } \\ \text { GID } & \text { Geometric Intersection Description } \\ \text { RSU } & \text { Road Side Unit } \\ \text { OBE } & \text { On-Board Equipment } \\ \text { BSM } & \text { Basic Safety Message } \\ \text { TMC } & \text { Traffic Management Center } \\ \text { DSRC } & \text { Dedicated Short Range Communications }\end{array}$




\section{CONTENTS}

List of Acronyms

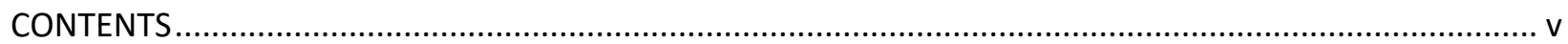

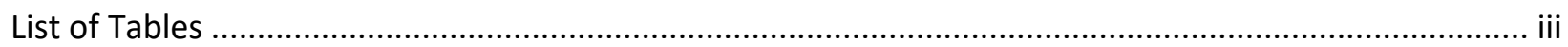

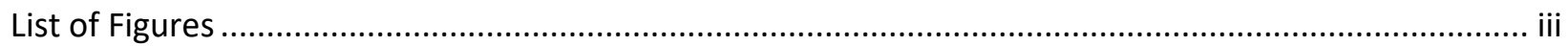

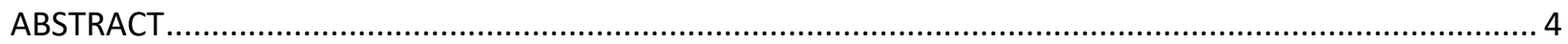

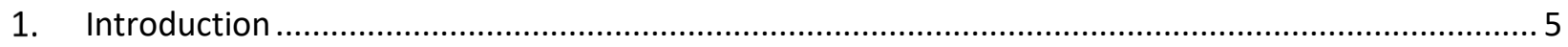

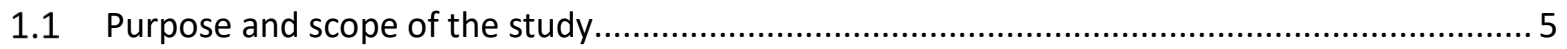

1.2 Connected vehicles vs connected and automated vehicles ............................................. 5

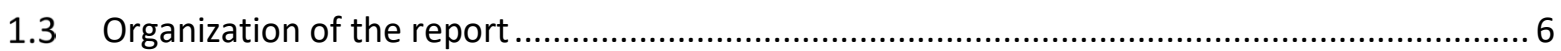

2. Signal Control in a Connected and Automated Environment....................................................... 6

2.1 Signal control application in a CV/CAV environment ........................................................ 7

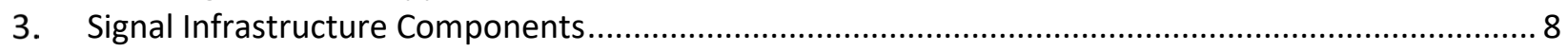

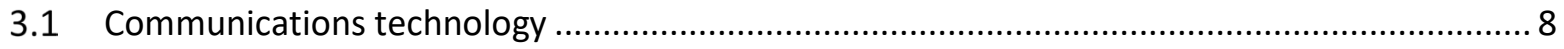

3.1.1 Dedicated Short Range Communications (DSRC) .............................................. 9

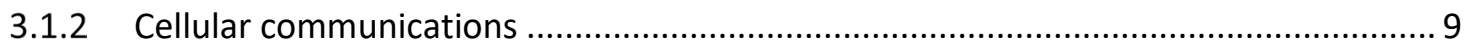

3.2 Road Side Unit (RSU) and On-Board Unit (OBU) …........................................................ 9

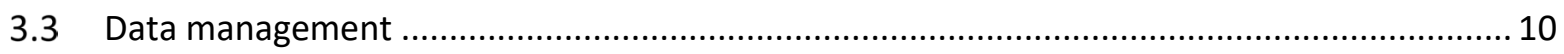

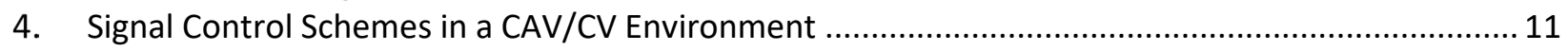

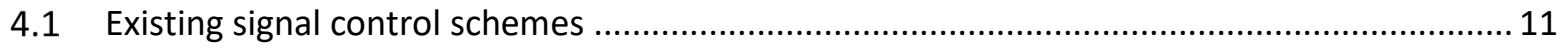

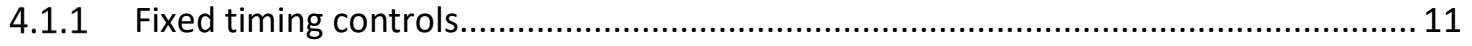

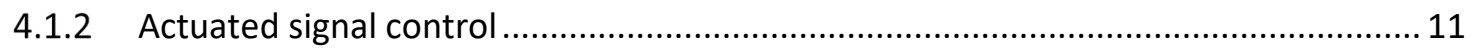

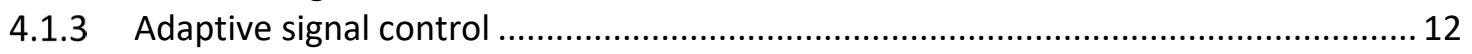

4.2 Recent advances in CV/CAV-based signal control algorithms ............................................ 12

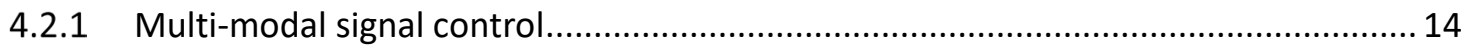

4.2.2 Autonomous intersection management.......................................................... 14

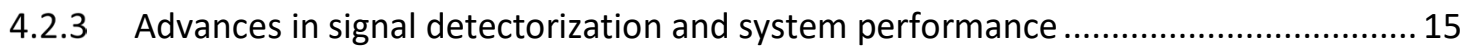

4.3 Transitions in infrastructure and signal control algorithms.................................................. 16

5. Signal Control Applications Review from Pilot Studies and Smart City Challenge ........................... 17

5.1 Safety pilot model deployment in Ann Arbor, Michigan .................................................... 17

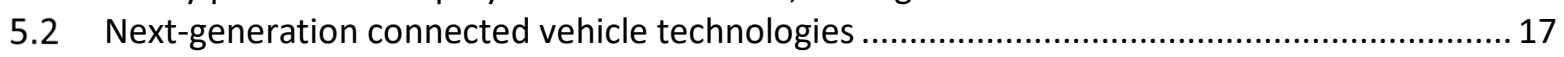

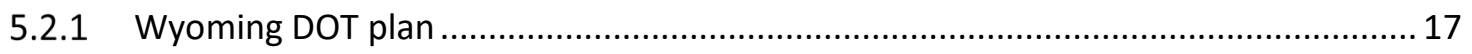

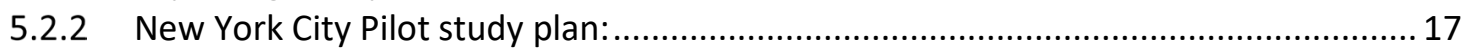

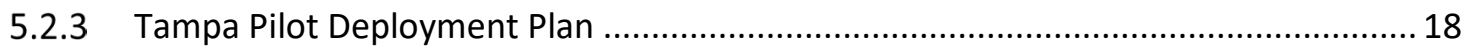

5.3 Smart City finalists" plan for signal control and infrastructure ............................................ 18

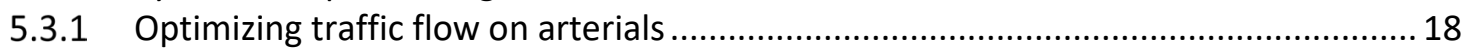

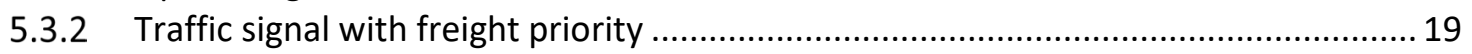

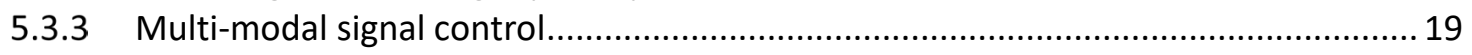

5.3.4 Traffic signal applications for users with disability ................................................ 19

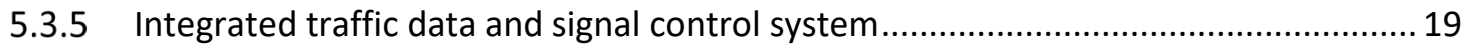

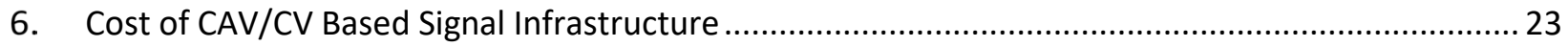

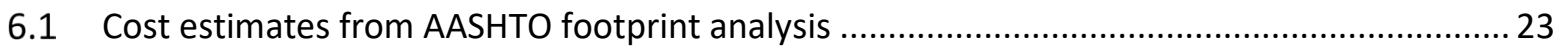

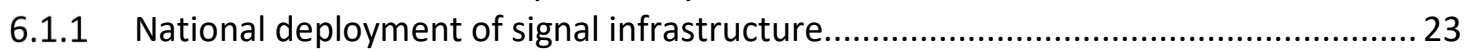

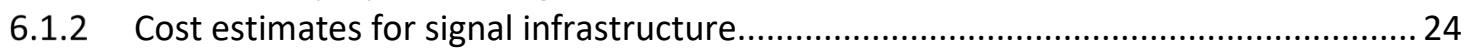

$6.2 \mathrm{CAV} / \mathrm{CV}$ deployment cost estimation using CO-PILOT ...................................................... 24 


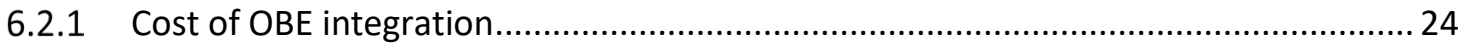

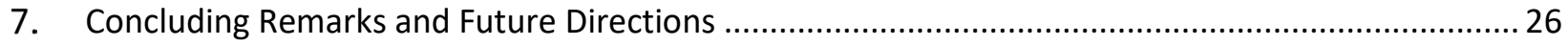

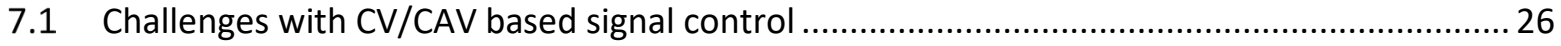

7.1.1 Impact of CV/CAV market share on performance of signal control applications........ 26

7.1.2 Investment for Road Side Units and Communication Backhaul .................................. 27

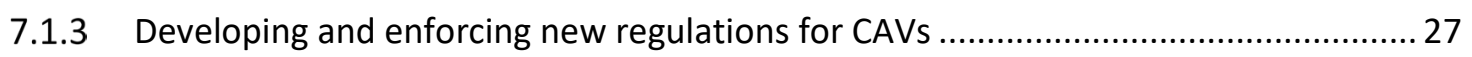

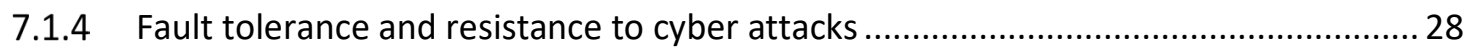

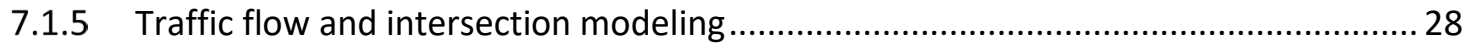

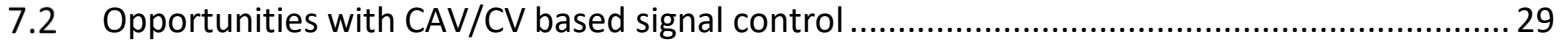

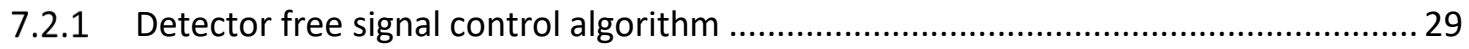

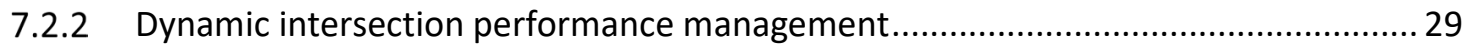

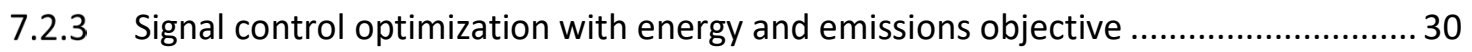

7.2.4 Air quality monitoring system using CAVs-Signal networks ..................................... 30 


\section{List of Tables}

Table 1 CAV/CV based signal control related applications .................................................................... 7

Table 2 Latency comparison of communication technologies in a CAV environment ............................... 8

Table 3 Proposed CV/CAV signal applications by the Smart City participants ......................................... 20

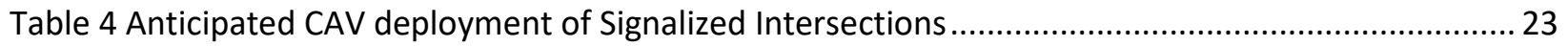

Table 5 Anticipated cost for signal infrastructure deployment (in 2013 US dollars)................................ 24

Table 6 Impact of market share on performance of CAV/CV based signal control algorithms .................. 26 


\section{List of Figures}

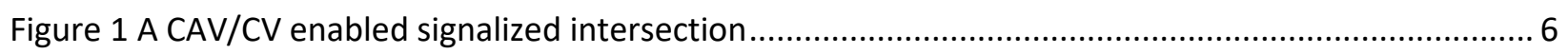

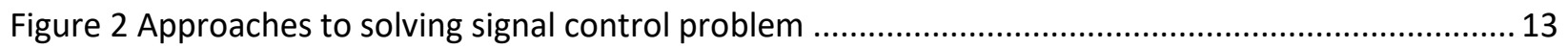

Figure 3 Transitions in signal infrastructure and control algorithms in CAV/CV environment .................. 16 


\begin{abstract}
Documenting existing state of practice is an initial step in developing future control infrastructure to be co-deployed for a heterogeneous mix of connected and automated vehicles with human drivers while leveraging benefits to safety, congestion, and energy. With advances in information technology and extensive deployment of connected and automated vehicle technology anticipated over the coming decades, cities globally are making efforts to plan and prepare for these transitions. CAVs not only offer opportunities to improve transportation systems through enhanced safety and efficient operations of vehicles. There are also significant needs in terms of exploring how best to leverage vehicle-to-vehicle (V2V) technology, vehicle-to-infrastructure (V2I) technology and vehicle-to-everything (V2X) technology. Both Connected Vehicle (CV) and Connected and Automated Vehicle (CAV) paradigms feature bidirectional connectivity and share similar applications regarding signal control algorithm and infrastructure implementation. The discussion in our synthesis study assumes the CAV/CV context where connectivity exists with or without automated vehicles.
\end{abstract}

Our synthesis study explores the current state of signal control algorithms and infrastructure, reports the completed and newly proposed CV/CAV deployment studies regarding signal control schemes, reviews the deployment costs for CAV/AV signal infrastructure, and concludes with a discussion on the opportunities such as detector free signal control schemes and dynamic performance management for intersections, and challenges such as dependency on market adaptation and the need to build a faulttolerant signal system deployment in a CAV/CV environment. The study will serve as an initial critical assessment of existing signal control infrastructure (devices, control instruments, and firmware) and control schemes (actuated, adaptive, and coordinated-green wave). Also, the report will help to identify the future needs for the signal infrastructure to act as the 'nervous system' for urban transportation networks, providing not only signaling, but also observability, surveillance, and measurement capabilities.

The discussion of the opportunities space includes network optimization and control theory perspectives, and the current states of observability for key system parameters (what can be detected, how frequently can it be reported) as well as controllability of dynamic parameters (this includes adjusting not only the signal phase and timing, but also the ability to alter vehicle trajectories through information or direct control). The perspective of observability and controllability of the dynamic systems provides an appropriate lens to discuss future directions as CAV/CV become more prevalent in the future.

Acknowledgment: This work is funded by the Vehicle Technology Office (VTO) of the Department of Energy(DOE) under the Energy Efficient Mobility Systems (EEMS) program. The report was highly benefitted from the suggestions of the DOE program managers. 


\section{Introduction}

\subsection{Purpose and scope of the study}

Connected automation in transportation systems could offer substantial benefits for reducing traffic crashes, improving mobility and accessibility, and minimizing environmental impacts such as fuel consumption and air quality. With advancements in information and communications technology (ICT) coupled with smart infrastructure systems, new approaches to integrated and connected transportation systems are being explored at the convergence of urban signal infrastructure with innovations in Connected and Automated Vehicles (CAVs). Extensive deployment of CAV technology over the next decades are anticipated and cities globally - from Austin, Nashville, Los Angeles, Columbus, Ann Arbor, Tampa, Pittsburgh, New York City, Denver, San Francisco and Boston in the United States; to Singapore; Gothenburg, Sweden; La Rochelle, France; Lausanne, Switzerland; Helsinki, Finland; London, England, Sao Paolo, Brazil, Tel Aviv Israel, Buenos Aires, Argentina, Paris, France, globally - are making efforts to plan and prepare for this transition. CAVs offer opportunities to improve transportation systems through enhanced safety and efficient operations of vehicles. CAVs not only offer opportunities to improve the transportation, but they also pose new challenges for optimal leveraging vehicle-to-vehicle (V2V) technology, vehicle-to-infrastructure (V2I) technology and vehicle-to-everything (V2X) technology. Considering the transitions in CAV deployment and signal infrastructure, it is important to develop robust and optimal control schemes that will be applicable for CAVs with fast, reliable V2V-V2I-V2X communications and a mixing of CAV and human drivers with limited communications. The study explores existing signal control infrastructure (devices, control instruments, and firmware) and control schemes (actuated, adaptive, and coordinated-green wave) and identifies the future needs for the signal control infrastructure to act as the 'nervous system' for urban transportation networks, providing not only signaling, but also observability, surveillance, and measurement capacity.

\subsection{Connected vehicles vs connected and automated vehicles}

Connected Vehicles (CV), and Connected, and Automated Vehicles (CAV) represent two different but related traffic environments. CV refers to communication among vehicles and nearby infrastructure and the vehicles can either be human-operated or autonomous. The USDOT's Intelligent Transportation System Joint Program Office (ITS JPO) characterizes Automated Vehicles (AV) with safety critical control functions such as steering, throttle, and braking without the direct intervention of the human driver. The ITS Strategic Plan 2015-2019 (Transportation et al., 2014) has a multimodal program for vehicle automation. According to the US DOT, automated vehicles can be fully autonomous, using only sensors and detection systems installed in the vehicle. Alternatively, the vehicles could be connected and use communications such as connected vehicle technology to communicate with other vehicles and roadside infrastructure. For either case, connectivity plays a critical role for the deployment of applications aiming at safety, mobility, and reducing environmental impact. CAV refers to an environment where automated vehicles ${ }^{1}$ can exchange data with nearby vehicles and infrastructure including roadside units and traffic signal controllers and may respond through driving actions to achieve an optimal state of traffic flow in the system. CAV environment offers an efficient and scalable deployment of applications and the CV paradigm will converge to CAV environment as technology and market adaptation evolve.

\footnotetext{
${ }^{1}$ The level of automation determines the level of human intervention in the driving task (U.S. Department of Transportation, 2016). The level of automation follows SAE J3016 (www.sae.org/autodrive)
} 


\subsection{Organization of the report}

The rest of the report is organized as follows: Section 2 provides an overview of different elements of signal control system in CAV/CV environment, Section 3 explores the signal infrastructure components, Section 4 reviews signal control schemes relevant to CAV/CV based applications, section 5 summarizes signal control applications from CAV/CV pilot studies and from proposals of Smart City Challenge finalists, Section 6 discusses the cost estimates for CAV/CV deployment, and finally, Section 7 concludes the report with potential challenges and opportunities for signal control and infrastructure with CAV/CV transition in the near future.

\section{Signal Control in a Connected and Automated Environment}

Communications between vehicles (V2V) and signal infrastructure (V2I) are continuously evolving in ways toward the design goals of becoming faster, safer, and more reliable. Indeed, wireless communications, on-board computer processing, advanced vehicle sensors and GPS offer examples of the shifts in network environments where signal infrastructure are providing improved conditions in urban environments (e.g. Figure 1). These technologies will allow approaching vehicles to provide realtime signals on approach speed and positions to signal control unit of a junction, which can then responsively adjust signal timing to improve traffic flows in terms of smooth flow and minimized transportation energy use inefficiencies. Thus, in a CAV/CV environment, vehicles work collaboratively with signal infrastructure in an active manner to maximize the network performance.

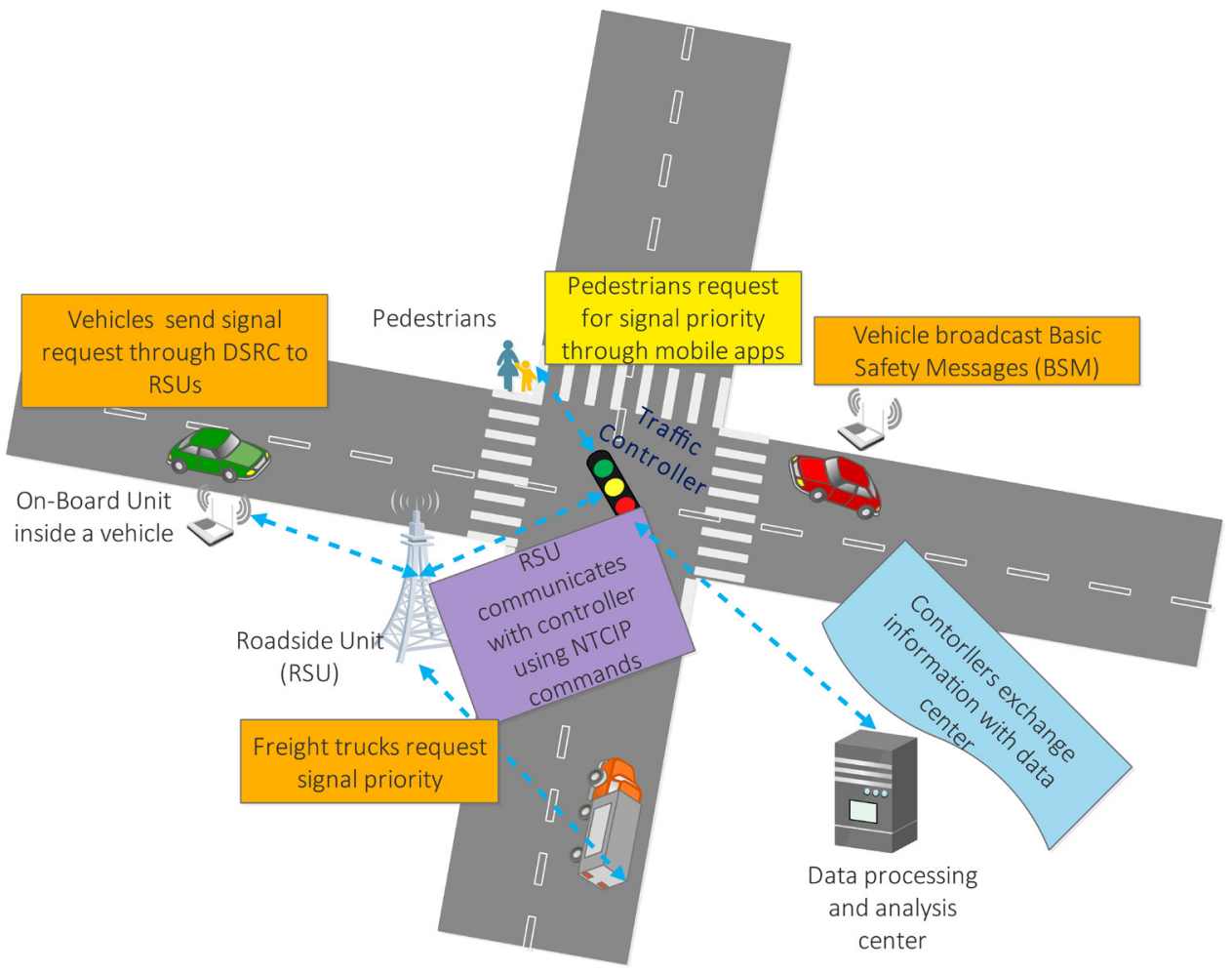

Figure $1 \mathrm{~A} C A V / C V$ enabled signalized intersection 


\subsection{Signal control application in a CV/CAV environment}

The CAV/CV based applications are growing and will be evolving over the next 20-30 years depending on the advancement of the technology, market adoption, and market needs (U.S. Department of Transportation, 2016; Wright et al., 2013a). Table 1 lists some CAV/CV based applications relevant to signal control. This is not a comprehensive list and applications are also evolving with the changes in technology and demand from user and system perspectives. Later we provide a list of signal control related applications as proposed by the Smart City Challenge participants (see section 5.3)

Table $1 \mathrm{CAV/CV}$ based signal control related applications

\begin{tabular}{|c|c|c|}
\hline Application & Communication type & Objective \\
\hline $\begin{array}{l}\text { Pedestrian in Signalized } \\
\text { Crosswalk }\end{array}$ & Vehicle to signal controller & Safety of the pedestrians \\
\hline $\begin{array}{l}\text { Emergency vehicle } \\
\text { preemption at traffic } \\
\text { signal }\end{array}$ & Vehicle to signal controller & Reduction of response time \\
\hline Transit signal priority & Vehicle to signal controller & Efficient transit operations \\
\hline $\begin{array}{l}\text { Multimodal Intelligent } \\
\text { Traffic Signal System } \\
\text { (MMITSS). } \\
\text { (see section } 4.4 \text { for } \\
\text { details) }\end{array}$ & $\begin{array}{l}\text { Communication between vehicles, } \\
\text { controllers, pedestrians, and other } \\
\text { modes of transportation }\end{array}$ & Co-optimizing across travel modes \\
\hline $\begin{array}{l}\text { Eco-Traffic signal } \\
\text { timing }\end{array}$ & Vehicle to signal controller & Reduce environmental impact \\
\hline $\begin{array}{l}\text { Eco-traffic signal } \\
\text { priority }\end{array}$ & Vehicle to signal controller & $\begin{array}{l}\text { Reduce environmental impact and } \\
\text { encourage the adoption of low- } \\
\text { emissions vehicles }\end{array}$ \\
\hline Red-light Warning & Vehicle to signal controller & Avoid red-light running collisions \\
\hline $\begin{array}{l}\text { Performance } \\
\text { assessment of } \\
\text { signalized intersections }\end{array}$ & Signal controller to data Unit & $\begin{array}{l}\text { Assessing performance of signal } \\
\text { timing plans and fine-tuning, } \\
\text { detection of power disruption, fault } \\
\text { detection }\end{array}$ \\
\hline $\begin{array}{l}\text { CV enabled Turning } \\
\text { Movement and } \\
\text { intersection analysis }\end{array}$ & Signal controller to data Unit & Impact studies, throughput analysis. \\
\hline
\end{tabular}




\section{Signal Infrastructure Components}

The signal infrastructure exists now was built for a different time and to serve a different type of vehicle. As a nation, we need to prepare our signal infrastructure to ensure an effective deployment of control applications in a CAV environment. Signal infrastructure is a critical element for the optimization of traffic flow at intersections, particularly in congested urban areas. Traditional signal controllers do not have the capability to send and receive information from vehicles and roadside units. CAV environment is expected to provide a high-resolution data exchange and facilitate advanced control algorithms operating with real-time data (Goodall et al., 2013). Traffic signal controllers are expected to interface with Road Side Units (RSUs) and CV/CAVs for applications utilizing Signal Phase and Timing (SPaT) data. Our study identifies four major elements of the signal infrastructure regarding CAV-based signal control optimization and deployment: (a) the communication technology that enables the bi-directional data exchange among vehicles, controllers, and roadside units, (b) the roadside units (either isolated or coupled with the traffic controller), (c) the on-board units inside the car, and (d) the data storage and processing unit for optimization and decision-making. The next few sections will provide a brief over on each element.

\subsection{Communications technology}

The two major competing candidates for communication technologies in a CV/CAV environment are Dedicated Short Range Communications (DSRC) and cellular communications. Other communications technologies used within traffic signaling may include Wi-Fi 802.11, Bluetooth, WiMax, Terrestrial Digital Radio, and Two-Way Satellite. Optimal solutions of a CV/CAV approach may include combinations of technologies to attain the most benefits. The range of all these communication technologies can go from $3 \mathrm{~m}$ to 3000 miles. The data exchange frequency and the coverage area for an application in CAV environment should determine the suitability of the communication technology. Table 2 compares the latency of different communication technologies.

Table 2 Latency comparison of communication technologies in a CAV environment

\begin{tabular}{|cl|}
\hline $\begin{array}{c}\text { Communication } \\
\text { Technology }\end{array}$ & \multicolumn{1}{c|}{ Latency } \\
\hline 5.9 GHz DSRC & $0.0002 \mathrm{~s}$ \\
\hline Cellular (up to 4G) & $1.5-3.5 \mathrm{~s}$ \\
\hline WiMax & $1.5-3.5 \mathrm{~s}$ \\
\hline Bluetooth & $3-4 \mathrm{~s}$ \\
\hline WiFi 802.11 & $3-5 \mathrm{~s}$ \\
\hline Terrestrial Digital Radio & $10-20 \mathrm{~s}$ \\
\hline Two-Way Satellite & $>60 \mathrm{~s}$ \\
\hline Anticipated 5G & $0.0001 \mathrm{~s}$ \\
\hline
\end{tabular}

Due primarily to latency requirement, DSRC and the anticipated $5 G$ standard for cellular communications are the primarily leading candidates to fulfill the V2I, V2V, and V2X roll within CAVs. 


\subsubsection{Dedicated Short Range Communications (DSRC)}

DSRC is the most used technology to facilitate the connectivity in CAV environment ${ }^{2}$ in existing demonstrations of V2V and V2I DSRC allows high-frequency two-way short-to-medium range wireless connectivity with low latency. Also, DSRC can ensure reliable connectivity in adverse weather conditions. With a focus on the intelligent transportation system based safety and mobility applications, the Federal Communications Commission (FCC) assigned a dedicated $75 \mathrm{MHz}$ of spectrum in the $5.9 \mathrm{GHz}$ band. The communication range of DSRC technology is about 300-500 m. Most safety applications in the CV environment use DSRC for V2V, V2I, and I2I communications. Other advantages of DSRC include interoperability and privacy protection for connected and automated vehicles. The Basic Safety Message (BSM) following SAE J2735 can broadcast messages ten times per second (10 Hz) with DSRC technology. Further, digital description of the roadway intersections-electronic maps, and Signal Phase and Timing (SPaT) data are also exchanged using the DSRC.

\subsubsection{Cellular communications}

With extensive market share and availability of cellphones, cellular technology is another potential candidate for facilitating communication in CAV/CV environment. Safety applications cannot be deployed with current $4 \mathrm{G}$ cellular connectivity because of the requirement of low latency (see Table 2 ). However, other applications for mobility, signal control, and environmental impact may use cellular technology. LTE (Long Term Evolution) is the most recent technology. LTE combines the benefits of GSM and CDMA and offers a wideband IP system with higher flexibility. LTE technology does not allow one mobile terminal to exchange data with a neighborhood terminal or data unit. It requires the presence of an RSU to facilitate the communication.

The next anticipated cellular evolution is $5 G$, which is still in incubation ${ }^{3}$, can be a potential candidate for the $\mathrm{CAV} / \mathrm{CV}$ environment ${ }^{4}$ requiring low latency communications. Two major features of $5 \mathrm{G}$ are low latency of sub-1 millisecond and accommodation of small and lower power devices compared to $4 \mathrm{G}$ networks. It is possible that future vehicular communications will be an optimal combination of DSRC and $5 \mathrm{G}$ where DSRC handles safety applications and $5 \mathrm{G}$ will offer passengers the data intensive entertainment features.

\subsection{Road Side Unit (RSU) and On-Board Unit (OBU)}

CAVs need to be equipped with on board units (OBU) to be able to communicate with the roadside equipment/units (RSU/RSE) and the controllers. Moreover, several connected vehicle pilot studies have used after-market safety devices that are installed in the vehicles (not necessarily autonomous vehicles) for specific safety and signal control applications. Commercial vendors including Econolite and Savari are developing devices and roadside units for CAV enabled applications. Econolite group and Savari Inc. have recently developed a partnership to provide infrastructure units in connected and automated environment ${ }^{5}$. Initially, the focus is on the V2I based safety applications. Savari has partnered with the

\footnotetext{
2 https://www.its.dot.gov/factsheets/dsrc factsheet.htm

${ }_{3}^{3}$ To find more details on testing periods please see http://www.rcrwireless.com/20170324/asia-pacific/softbank-5g-tests-tag17

${ }^{4}$ http://spectrum.ieee.org/cars-that-think/transportation/self-driving/autonomous-driving-experts-weigh-5g-cellular-networkagainst-shortrange-communications-to-connect-cars

${ }^{5}$ https://www.econolitegroup.com/blog/econolite-group-savari-partner-accelerate-connected-automated-vehicletechnologies-deployment/
} 
cities participating both in the USDOT Smart City Challenge ${ }^{6}$ and Connected Vehicle (CV) Pilot Deployment Program.

Further, for pedestrian and bicyclist safety focused intersection applications, pedestrians and bicyclists should have devices that can send request to the controller for a priority phase. The New York City pilot study proposes to equip the pedestrians and bicyclists with after-market safety devices. In addition, specific apps can be installed in the smartphones of the travelers with special needs and the smartphone can send signal phase request automatically to the controllers.

According to the US DOT report (Hill, 2013; Hill and Garrett, 2011) for Vehicle-to-Infrastructure integration, the automobile manufacturers are required to equip vehicles with on-board equipment (OBE) that includes a communications device, a positioning device, a processing platform, and application software. Furthermore, the OBEs will communicate with roadside equipment (RSE) to facilitate V2I applications and with other OBEs for V2V applications. The automotive industry plays a critical role in terms of availability and manufacturing of the OBUs. Each automotive original equipment manufacturer (OEM) may have its own model of CAVs with distinctive features. Besides the automanufacturers, Google is building its own model of CAVs. Further, there is a growing industry for motion sensors, and aftermarket add-ons particularly for CAVs (e.g., MobileEye offers sensors for collision avoidance). The distinction between vehicle vendors are likely within automation, but the connectivity portion will need to be standard, as with DSRC, to provide the information needed the signal controller to enhance overall traffic flow.

\subsection{Data management}

Collecting, processing, and analyzing data from CAV/CV environment is a challenging task. For an effective deployment of signal optimization in a CAV/CV environment, it is critical to build a data management system that allows for real-time analytics and synched operations with the signal controller for adjusting timing plans. The Connected Vehicle Reference Implementation Architecture $(\text { CVRIA })^{7}$ developed by the U.S. DOT provides pointers to the standards focusing on interoperability and efficiency. It is important to identify existing and future data needs and availability specific to signal control applications. At the same time, the responsible entity should define level of data access, data ownerships, data maintenance roles, and extents of data sharing among different entities within a jurisdiction. The US DOT Research Data Exchange ${ }^{8}$ stores CV/CAV testbed data and offers a data sharing platform open to public. Other important aspects include fusion of stationary (from RSUs) and mobile data (e.g., from CAVs), development of GIS-based data visualization platform, and privacy protection. The Michigan Data Use Analysis and Processing (DUAP) project (Mixon et al., 2012) is one of the first studies dealing with the data management in a CV/CAV environment. The DUAP project was initiated to assist the Michigan Department of Transportation (MDOT) and its partners to assess the use of connected vehicle data in transportation agency management and operations. The DUAP project explored the processes and challenges to collect, aggregate, process and provide data from CAV/CV environment and to use the data for applications related to traffic signal optimization, traffic impact studies, bridge and road maintenance, and estimation of origin-destination flows.

\footnotetext{
${ }^{6}$ https://www.transportation.gov/smartcity

${ }^{7}$ http://local.iteris.com/cvria/

8 https://www.its-rde.net/
} 


\section{Signal Control Schemes in a CAV/CV Environment}

This section reviews the traditional signal timing plans-fixed, actuated, and adaptive control schemes, the recent advances in the control algorithms that leverage the connected and automated vehicle environment, and the most advanced autonomous intersection management techniques that do not require the presence of physical traffic lights.

\subsection{Existing signal control schemes}

Existing signal control schemes can be categorized into three major groups: fixed timing control, adaptive control, and actuated and semi-actuated controls. Rajasri et al.(2015) and Stevanovic (2010) summarize current implementation of signal control algorithms in the US. Actuated and adaptive controls are mostly implemented with static detection devices such as hardware inductive loop detectors, video cameras, magnetic detectors, and laser radar. The traffic detection Handbook (Federal Highway Administration, 2006) provides more details on the detection technology.

\subsubsection{Fixed timing controls}

In fixed timing control, the Green, Red, and Yellow durations at road junctions are static regardless of the actual traffic conditions (Gordon and Tighe, 2005; TTI, 2012) for a given period. Most cases the timing plan and cycle lengths are designed based upon historic traffic data representing traffic flow patterns at different times of the day (TOD). The disadvantage of such a scheme is that it is an open-loop control infrastructure in that it cannot adjust in real-time to variations in traffic flow. It is closed-loop in a sense, in that one every three to ten years the local jurisdiction may perform a study to adjust the timing parameters, but once the timing patterns are established they remain static until the next study is performed. Fixed time control systems still dominate the industry with timing plans updated periodically (typically three to five years), to reflect changing demand characteristics.

\subsubsection{Actuated signal control}

Actuated signal control allows the signal controller to respond to changing situations somewhat like adaptive control, but is constrained by a fixed signal system architecture. In actuated control, the sensors are used to better allocate excess green time, and in many instances, are used on minor movements or side street movements. For example, in actuated control a sensor in the left turn lane may detect the end or absence of a left turn queue, and thus give additional time to the opposing through movement. Also, side street detector loop detectors at minor intersection are frequently used to govern whether any green time is allotted, allowing more green time progression along the main corridor in the absence of side street traffic. Actuated control is not uncommon, and the existing infrastructure of detectors serves primarily for actuated signal control, which includes stop bar detection and approach detection. Although many technologies have been employed for detection (magnetic loop, radar, image and video), the outputs are presence (occupied versus unoccupied zone) for use in existing signal controllers. 


\subsubsection{Adaptive signal control}

To overcome difficulties with fixed timed control, adaptive signal controls have been developed and used for some corridors and junctions in the United States, though adoption is not limited. The state of the art of these signal control systems can be found in several well-documented surveys. Major areas include computer intelligence based urban traffic signal control (Zhao et al., 2012), adaptive signal control (Qureshi and Abdullah, 2013; Rajasri et al., 2015). Also, with the increased availability of data collected from diverse sources, data-driven intelligent transportation system has been proposed in recent years. Data-driven approaches have been used for control and decision making of transportation systems so as to optimize its operational performance(Zhang et al., 2011). More recently, reliability based traffic signal control (Zheng et al., 2016)has been proposed for urban arterial roads and a framework has been proposed for the evaluation of the consequences of signal control tactics on reliability and the expected values of travel time. More studies are summarized in Skabardonis et al. (2013) and Stevanovic et al. (2010).

As with actuated control, the input data for adaptive control are presence detectors (approach and stop bar detection). The presence and dissipation of queues are not directly measured but derived from the existing network of presence detectors. This presents not only challenges for the control system input, but also fundamentally limits the performance feedback on the effectiveness of modern adaptive control systems.

\subsection{Recent advances in CV/CAV-based signal control algorithms}

Skabardonis et al. (2013) reported and summarized several advanced traffic signal control algorithms under CV environment based upon the works performed by the California PATH Program at the University of California at Berkeley in cooperation with the California Department of Transportation (Caltrans), and the Federal Highway Administration (FHWA) of the US Department of Transportation. In this project, algorithms for the estimation of performance measures (MOEs) based on CV data were developed and several signal and lane control concepts were established and tested for improved mobility and safety. Also, a prototype system was also developed and field-tested to provide real-time speed advisories to drivers on the ways to minimize fuel consumption and emissions. This presents a whole envelope of traffic signal operation where both the signal control and advice to the drivers are generated using the communication capability and smart algorithms - representing a future implementation of the advanced traffic signal control for CVs.

Goodall et al. (2013) proposed a predictive microscopic simulation algorithm for traffic signal control under CV environment. It has been reported that by predicting the locations of the vehicles in a short period via rolling time horizon and using such a prediction for signal control, the whole system can further reduce the traffic flow delays by $8.3 \%$ at the $75 \%$ penetration of CVs. In (Ilgin Guler et al., 2014a), study has been carried out that improves the efficiency of the intersections using CV technology. Making use of the speed and position data of individual vehicles, it has been reported that the proposed algorithm optimizes the traffic operation for a one-way street with a certain rate of $\mathrm{CV}$ penetrations $(0 \%$ - 60\%). In(Feng et al., 2015), a real-time adaptive signal control for CV environment has been developed, where a real-time adaptive signal phase allocation algorithm is obtained using connected vehicle data to optimize the phase sequence and duration by solving a two-level optimization problem that minimizes total vehicle delay and the queueing length. In the proposed work, different rate of CV penetration has been considered, and it has been claimed that average delay can be reduced by $16.33 \%$, showing a clear 
advantage of using the communication capabilities of the CVs to optimize the traffic signal control. However, the algorithm is only validated for a single junction using simulation tools, and further study is therefore needed for multiple junctions over a networked traffic flow area.

Further, it is critical to enable coordinated movement of vehicles through a corridor to minimize stops. These methods, sometimes referred to as a green-wave, platooning, or corridor signal coordination attempts to take advantage of pulse vehicle flow through a corridor or network to minimize stops and delay (Bazzan et al., 2010; Hu et al., 2015; Jacob and Abdulhai, 2006; Zhu et al., 2015). This is a contrast to the random arrival patterns assumed for an isolated intersection. Another issue is that different composition of vehicles should also be considered together with the movements of pedestrians and bicycles. The next subsections review a few CAV/CV based signal control applications.

This report does not focus much on the control methodologies partly because our objective is to explore more on the CV/CAV based applications. The following figure provides the major approaches to signal control optimization ranging from mathematical optimization to state-of-art machine learning techniques.

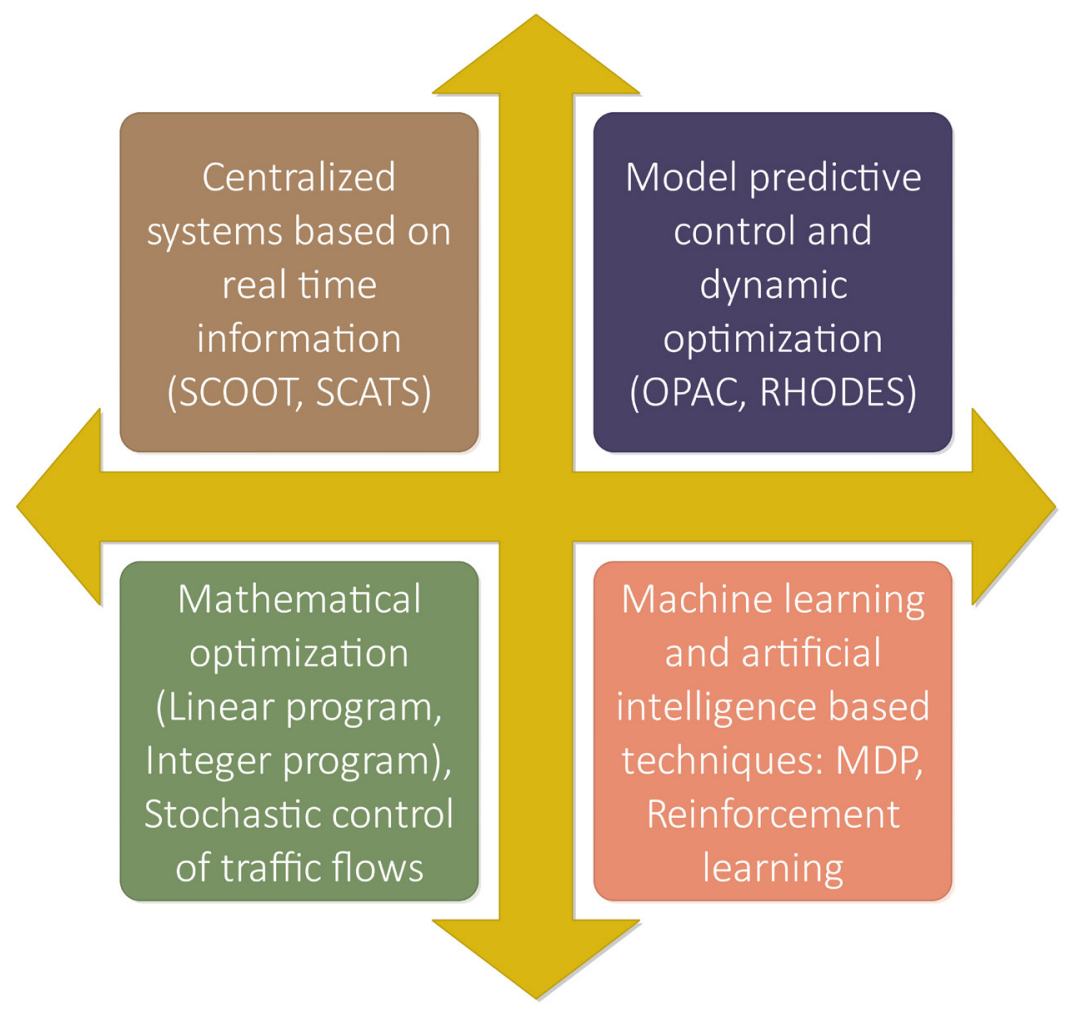

Figure 2 Approaches to solving signal control problem

Next, we discuss specific signal control applications in CV/CAV environment. 


\subsubsection{Multi-modal signal control}

One major initiative of the CV/CAV based signal control applications is the Multimodal Intelligent Traffic Signal System (MMITSS). The MMITSS ${ }^{9}$ is a next-generation traffic signal system that will serve all modes of surface transportation including passenger cars, transit, emergency vehicles, pedestrians, and bicyclists (Hill, 2013). The control scheme will optimize the performance of an arterial accounting for the heterogeneous flow of traffic. Applications within the MMITSS include:

\subsubsection{Intelligent Traffic Signal System (ISIG)}

The objective is to maximize the traffic passing through the signalized intersection in real-time. The controller receives information on vehicles approaching the intersection using V2I and V2V communications and adjusts the signal timing parameters in real-time.

\subsubsection{Transit Signal Priority (TSP)}

The objective is to improve transit operations by providing priority at the signalized intersections considering factors such as number of passengers on a bus, optimizing schedule delay, and predicted travel time for the transit routes. For instance, an OBE-equipped bus can send information on passenger counts, the lag in scheduled time of arrival, and service priority to the signal controller. Based on the data the signal controller will adjust the timing plan to maximize the performance of the bus service.

\subsubsection{Mobile Accessible Pedestrian Signal System (PED-SIG)}

The objective is to attain pedestrian safety at signalized intersections and assist visually impaired pedestrians at crosswalks. The controller exchanges data with the pedestrian via an on-person mobiledevice, which can be simply a smart phone application or after-market device, and adjust the pedestrian phase in the signal timing plan.

\subsubsection{Emergency Vehicle Preemption (PREEEMPT) and Freight Signal Priority (FSP)}

PREEMPT allows the emergency vehicle to pass the intersections with minimal delay. The controller either obtains data from a centralized server or from the emergency vehicle as it approaches the intersection. For FSP, the objective is to increase travel time reliability for freight operations accounting for the safety and mobility of other transportation modes using the signalized intersection. Arizona and California has two testbeds where they have implemented the multi-modal signal controls.

\subsubsection{Autonomous intersection management}

The CAV environment can also lead to a scenario where we do not need the physical presence of traffic lights at intersections. Initial work started back in 2006 at the University of Texas, Austin (Dresner and Stone, 2008). Control algorithms find the conflict free trajectories within the intersections (Fajardo et al., 2011; Zhu and Ukkusuri, 2015). Major approaches include optimal reservation based schemes(Levin et al., 2016; Li et al., 2013), auction-based control (Carlino et al., 2013), and linear programming based solutions (Zhu and Ukkusuri, 2015). A novel linear programming formulation was established for autonomous intersection control that accounts for traffic dynamics within a connected vehicle environment, where a lane based bi-level optimization model is constructed to propagate traffic flows in

\footnotetext{
${ }^{9}$ https://www.its.dot.gov/research archives/dma/bundle/mmitss plan.htm
} 
the network. The authors claimed that the traffic flows from different lanes can pass through the conflict points of the intersection safely and there are no holding flows in the solution. Autonomous intersection management is a rising research area and more significant works in the next few years.

\subsubsection{Advances in signal detectorization and system performance}

Apart from CAV/CV, several advances in signal performance assessment, enabled through improved communications with signal controllers and new detection methods have advanced in recent years (Hainen et al., 2015). High bandwidth connectivity combined with central data storage and processing capability enabled detector along with all SPaT data to be collected and logged centrally at 1/100 second time resolution. This High-Resolution Control Data (HRCD) allows for significantly improved observability of the existing fixed-time and actuated system performance. The percent occupancy stop bar detectors relative to signal transitions allows for assessment of queue dissipation. Similarly, approach sensors relative to cycles green times provides feedback on quality of progression (percent of vehicles stopping versus progressing through on green) within a corridor. Similarly, data from reidentification sensors that use signals of opportunity from Bluetooth and WiFi devices provide accurate travel time samples for a large percentage of the travel stream (from 3\% to 25\%) allowing performance to be statically characterized in travel time probability density functions on an ongoing basis, providing a fundamental improvement in the observability of system performance. Although not used in real-time control, statistical travel time performance characterization combined with HRCD provides enhanced closed-loop control for re-timing of fixed and actuated systems (Young et al., 2016). Experimental application of these techniques using data produced by vehicles that self-report location and speed (CV data as well as probe data from commercial traffic vendors) allow scalability of system performance system wide without the need for fixed-based sensors (Krohn et al., 2017; Talukder et al., 2017). 


\subsection{Transitions in infrastructure and signal control algorithms}

With these discussions on infrastructure and control algorithms in CV/CAV environment, we recognize the transition as both in technologies and approaches to solve the signal control problem. The following figure shows the transition pattern. Transitions will happen in the automotive and communications technology as well as in the infrastructure including CV/CAV enabled intersections and possibly smart intersections without physical traffic lights. As communication capabilities advance, it is possible to design and implement control algorithms that can leverage the $\mathrm{V} 2 \mathrm{~V}, \mathrm{~V} 2 \mathrm{I}, \mathrm{V} 2 \mathrm{X}$ and $\mathrm{I} 2 \mathrm{I}$ and the data available in real time.

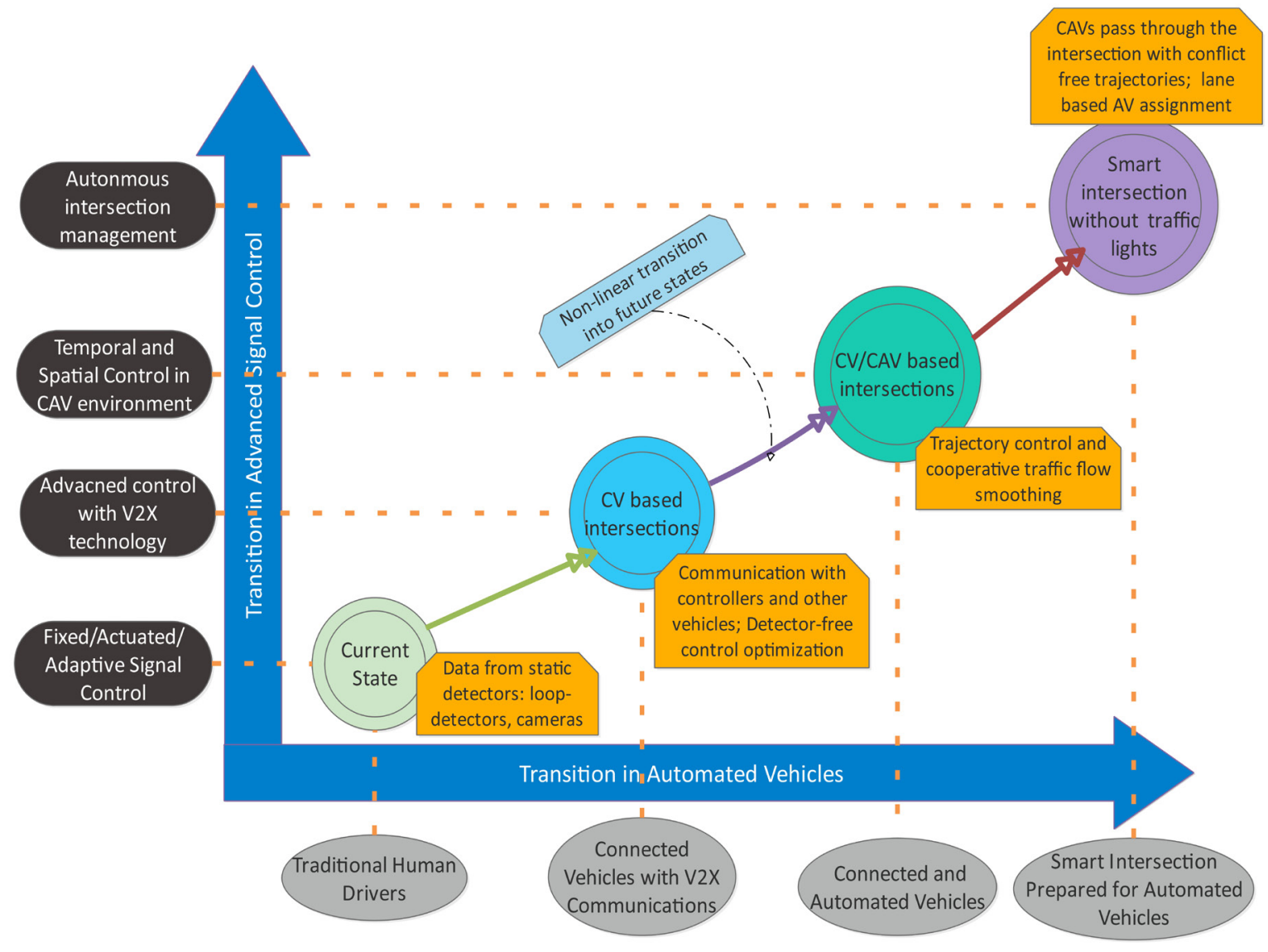

Figure 3 Transitions in signal infrastructure and control algorithms in CAV/CV environment

We also anticipate these transitions will not happen in a linear manner and many uncertainties will be unveiled as we progress. Nevertheless, the automotive industries and the transportation infrastructure managing entities should prepare for the transition and cooperate to reach a minimal energy-maximum mobility future. 


\section{Signal Control Applications Review from Pilot Studies and Smart City Challenge}

This section reports signal control applications as found in the recent and future planned pilot studies. Further, we summarize the signal control application efforts described in the Smart City Challenge participants.

\subsection{Safety pilot model deployment in Ann Arbor, Michigan}

The US DOT funded about $\$ 31$ million for the safety pilot deployment project at Ann Arbor, Michigan for the years 2012-2014 (Bezzina and Sayer, 2015). The project involves 2843 vehicles including passenger cars, trucks, buses, motorcycles, and a bike. On-board units and road-side units communicated using primarily DSRC. The network includes 73 lane-miles of roadway with 27 RSUs. The output data contains 110 billion DSRC Basic Safety Messages (BSMs) over 38 million miles of driving. Vehicle OBUs and RSUs shared information related to safety applications (BSM), geometry (MAP), and signal phasing and timing (SPaT). Based on the research data and model deployment, NHTSA made a decision to move forward with V2V communication for light-duty vehicles in 2014.

\subsection{Next-generation connected vehicle technologies}

The US DOT funded the Connected Vehicles Pilot Deployment Program ${ }^{10}$ in 2015 with a total of $\$ 42$ million in New York City, New York; Tampa, Florida; and rural Wyoming ${ }^{11}$. This is a part of the national connected vehicle deployment program.

\subsubsection{Wyoming DOT plan ${ }^{12}$}

The primary goal of the pilot deployment program is to develop applications leveraging V2I and V2V communications focusing on safe freight movement along the 1-80 corridor during critical weather conditions such as snow in the winter and fog, high winds during summer. The applications include roadside alerts, advisories, dynamic route guidance, and parking notification. The communication is mostly the basic safety message using DSRC and satellite communications. WYDOT provides task-specific cost estimation for the deployment. The cost for installing RSUs are not indicated separately, and it is mentioned that the cost estimates are determined based on discussion with the vendors.

\subsubsection{New York City Pilot study plan ${ }^{13}$ :}

The New York City Pilot led by the New York City DOT focuses on the safety of travelers and pedestrians in a connected vehicle environment. The traffic safety objectives highly reflect the Vision Zero ${ }^{14}$ initiative, which is one of major thrusts of New York City. This deployment involves approximately 310 signalized intersections accommodating V2I communications through DSRC technology. Specific applications include: (a) Reduce crashes between vehicles and pedestrians/bicyclists: Pedestrians and bicyclists will be equipped with transmitter device and send data to the signal controller. Further, a mobile accessible pedestrian signal system was developed that can make an automated call from a visually impaired pedestrian to the traffic signal and the signal sends the information to the vehicles

\footnotetext{
${ }^{10}$ https://www.its.dot.gov/pilots/

11 https://www.its.dot.gov/pilots/cv pubs.htm

12 https://www.its.dot.gov/pilots/pilots wydot.htm

13 https://www.its.dot.gov/pilots/pilots nycdot.htm

${ }^{14}$ http://www1.nyc.gov/site/visionzero/index.page
} 
near the intersection, (b) Intelligent Signal System with CV Data (I-SIGCVDATA): This will integrate the "Midtown in Motion" adaptive signal control system with CV technologies, and (c) Red light violation warnings

All these applications are suitable to deploy in the CAV environment as well and can increase the efficiency of the system regarding congestion alleviation and environmental impact.

The deployment plan mentioned that the acquisition process would involve 100 Aftermarket-Safety-

Device (ASD) and 10 Road-Side Units (RSU) from a single vendor. Afterward, the city will determine how many and which vendors to use based on maintenance cost, potential benefit, and non-recurring engineering cost analysis.

\subsubsection{Tampa Pilot Deployment Plan ${ }^{15}$}

The Tampa Hillsborough Expressway Authority (THEA) leads the Tampa, Florida CV deployment project. $\mathrm{V} 2 \mathrm{~V}$ and $\mathrm{V} 2 \mathrm{I}$ communication based application will be developed aiming at congestion reduction, safety improvement, and minimizing environmental impact. Applications relevant to traffic signal operations include: Mobile Accessible Pedestrian Signal System (PED-SIG) that prioritizes pedestrian phases in the signal-timing plan, Intelligent Traffic Signal System (I-SIG), Transit Signal Priority (TSP) particularly for Bus Rapid Transit, and Red Light Violation Warning.

The traffic management center (TMC) currently manages a network of Advanced Traffic Controllers, ATC 5201, and NEMA TS2 controllers. The traffic management application uses the National Institute of Standards and Technology (NIST) time server to send accurate time of day timing plan to all controllers connected to the traffic server. In the case of TMC failure, each controller recognizes the time of day via counting $60 \mathrm{~Hz}$ power line cycles.

\subsection{Smart City finalists" plan for signal control and infrastructure}

The US DOT initiated the Smart City Challenge ${ }^{16}$ in December 2015 where mid-sized cities in the US submitted proposals envisioning a smart transportation system leveraging technology, innovations, data, and connectivity. A total of 78 cities participated and submitted proposals focusing on the transportation challenges along with potential solutions. The US DOT selected seven finalists among the 78 participants and Columbus, Ohio won the challenge and was granted $\$ 40$ million by the US DOT, with an additional \$10 million funding and support from Vulcan. The proposals by the seven finalist cities include deployment of connected vehicle technologies and smart infrastructure to support applications in a connected and automated environment. For instance, the seven finalists planned for 1,000 advanced traffic signals and 13,000 CV/CAVs with DSRC. Moving vehicles through traffic signals with safety, efficiency, and reliability was identified by the finalists as one of the major challenges (US DOT, 2016).

\subsubsection{Optimizing traffic flow on arterials}

Suboptimal traffic signal control is a major reason of traffic delays in congested urban networks. Smart City participants emphasized the needs to implement traffic signal control schemes and to manage intersections in a smarter way leveraging the communication technology and data availability. Denver,

${ }^{15}$ https://www.its.dot.gov/pilots/pilots thea.htm

${ }^{16}$ https://www.transportation.gov/smartcity 
Colorado proposed to integrate adaptive signal control and smart freeway ramp metering for two major arterial highways (US DOT, 2016). Using the real-time sensor data, the timing plans would be adjusted to allow for smooth merging into freeways and avoidance of queue spillback into the arterials. Further, Furthermore, Denver also proposed to develop dynamic traffic signal control that will use the data from DSRC capable vehicles in the CAV/CV network.

\subsubsection{Traffic signal with freight priority}

Several Smart City participants proposed to improve reliability of freight by adjusting the signal control settings on freight corridors that would prioritize truck movements. Moreover, the control schemes will assist to form platooning which will lead to minimization of fuel consumption and emissions. Denver and San Francisco are among the cities that proposed freight signal prioritization in the vision of smart transportation.

\subsubsection{Multi-modal signal control}

Among the Smart City participants, 53 cities emphasized establishing connectivity among vehicles, pedestrian, bicyclists, controller, and surrounding infrastructure, creating multi-modal signal control. The proposal developed by San Francisco focused on safety and transit performance. The plan involved developing DSRC based signal control system at locations where pedestrian crashes are high and prioritizing transit movement to improve reliability.

\subsubsection{Traffic signal applications for users with disability}

Portland, Oregon proposed to develop mobile apps that will assist users with disability. The bidirectional data application would inform the authority of the travel patterns of users with disabilities, in order to help in building smart intersections. The proposed system would communicate with the app when user is in the intersection.

\subsubsection{Integrated traffic data and signal control system}

A unified traffic analytics platform that connects all infrastructure components is envisioned in the proposals of 45 Smart City participants. The winner Columbus, Ohio plans for a central connected traffic signal and transportation data to provide service to users and infrastructure components such as smart signal control. The Columbus Traffic Signal System (CTSS) project (\$76.2 million) will replace all 1,250 signalized intersections within Columbus and Central Ohio Region, along with installation of 565 miles of fiber optic cable, and over 100 new or updated traffic flow cameras at CTSS sites. This system provides the ability for inter-jurisdictional communication enabling the sharing of video and traffic data and coordination of traffic signals between agencies. Table 3 reports a summary CAV/CV based strategies related to signal control from the seven finalists in the USDOT Smart City competition. The table extracted from Smart City Challenge dataset provided by the US DOT ${ }^{17}$

\footnotetext{
${ }^{17}$ https://data.transportation.gov/Research-and-Statistics/Smart-City-Challenge-Finalists-Project-Proposals/4zfzamsd/data\#column-menu
} 
Table 3 Proposed CV/CAV signal applications by the Smart City participants

\begin{tabular}{|c|c|c|c|c|}
\hline City & State & Challenge & Vision Element & Strategy \\
\hline Austin & $\mathrm{TX}$ & Pedestrian / Bicyclist Safety & $\begin{array}{l}\text { Intelligent, Sensor-based } \\
\text { Infrastructure }\end{array}$ & Pedestrian Detectors (intersections) \\
\hline Austin & TX & Freight Delays / Congestion & Urban Delivery and Logistics & Freight Signal Priority \\
\hline Austin & $\mathrm{TX}$ & $\begin{array}{l}\text { Accessibility for People with } \\
\text { Disabilities and the Elderly }\end{array}$ & $\begin{array}{l}\text { User-Focused Mobility Services and } \\
\text { Choices }\end{array}$ & Apps for People with Disabilities \\
\hline Austin & $\mathrm{TX}$ & $\begin{array}{l}\text { Vehicle / Vehicle Collisions } \\
\text { (intersections) }\end{array}$ & Connected Vehicles & Intersection Movement Assist (IMA) \\
\hline Austin & $\mathrm{TX}$ & Delays at Intersections & Connected Vehicles & MMITSS / I-Sig \\
\hline Austin & $\mathrm{TX}$ & Freight Delays / Congestion & Connected Vehicles & Freight Signal Priority \\
\hline Austin & $\mathrm{TX}$ & $\begin{array}{l}\text { Unpredictable / Unreliable Transit } \\
\text { Service }\end{array}$ & Connected Vehicles & Transit Signal Priority \\
\hline Columbus & $\mathrm{OH}$ & Freight Delays / Congestion & Urban Delivery and Logistics & Platoon Signal Priority \\
\hline Columbus & $\mathrm{OH}$ & Freight Delays / Congestion & Urban Delivery and Logistics & Freight Signal Priority \\
\hline Columbus & $\mathrm{OH}$ & Freight Delays / Congestion & Urban Delivery and Logistics & Truck Platooning \\
\hline Columbus & $\mathrm{OH}$ & $\begin{array}{l}\text { Unpredictable / Unreliable Transit } \\
\text { Service }\end{array}$ & Connected Vehicles & Transit Signal Priority \\
\hline Columbus & $\mathrm{OH}$ & Pedestrian / Bicyclist Safety & $\begin{array}{l}\text { Intelligent, Sensor-based } \\
\text { Infrastructure }\end{array}$ & Pedestrian Detectors (intersections) \\
\hline Columbus & $\mathrm{OH}$ & Freight Delays / Congestion & Connected Vehicles & Freight Signal Priority \\
\hline Columbus & $\mathrm{OH}$ & Red Light Violations & Connected Vehicles & Red Light Warning Violation \\
\hline Columbus & $\mathrm{OH}$ & Delays at Intersections & Connected Vehicles & MMITSS / I-Sig \\
\hline Columbus & $\mathrm{OH}$ & $\begin{array}{l}\text { Poor Air Quality / Harmful Vehicle } \\
\text { Emissions }\end{array}$ & Connected Vehicles & $\begin{array}{l}\text { Eco-Approach and Departure at } \\
\text { Signalized Intersections }\end{array}$ \\
\hline Denver & $\mathrm{CO}$ & Freight Delays / Congestion & Connected Vehicles & Freight Signal Priority \\
\hline Denver & $\mathrm{CO}$ & Freight Delays / Congestion & Urban Delivery and Logistics & Freight Signal Priority \\
\hline
\end{tabular}




\begin{tabular}{|c|c|c|c|c|}
\hline City & State & Challenge & Vision Element & Strategy \\
\hline Denver & $\mathrm{CO}$ & Freight Delays / Congestion & Urban Automation & Truck Platooning \\
\hline Denver & $\mathrm{CO}$ & Delays on Freeways & Connected Vehicles & Ramp Metering \\
\hline Denver & $\mathrm{CO}$ & Delays at Intersections & Connected Vehicles & MMITSS / I-Sig \\
\hline Kansas City & MO & Red Light Violations & Connected Vehicles & Red Light Warning Violation \\
\hline Kansas City & MO & Freight Delays / Congestion & Connected Vehicles & Freight Signal Priority \\
\hline Kansas City & MO & $\begin{array}{l}\text { Limited Tools to Support Data Driven } \\
\text { Decision Making }\end{array}$ & Urban Analytics & Congestion and Traffic Analytics \\
\hline Kansas City & MO & $\begin{array}{l}\text { Vehicle / Vehicle Collisions } \\
\text { (intersections) }\end{array}$ & Connected Vehicles & Intersection Movement Assist (IMA) \\
\hline Kansas City & MO & Freight Delays / Congestion & Urban Delivery and Logistics & Freight Signal Priority \\
\hline Kansas City & MO & Delays at Intersections & Connected Vehicles & MMITSS / I-Sig \\
\hline Kansas City & MO & $\begin{array}{l}\text { Unpredictable / Unreliable Transit } \\
\text { Service }\end{array}$ & Connected Vehicles & Transit Signal Priority \\
\hline Kansas City & MO & $\begin{array}{l}\text { Accessibility for People with } \\
\text { Disabilities and the Elderly }\end{array}$ & $\begin{array}{l}\text { User-Focused Mobility Services and } \\
\text { Choices }\end{array}$ & Apps for People with Disabilities \\
\hline Kansas City & MO & $\begin{array}{l}\text { Poor Air Quality / Harmful Vehicle } \\
\text { Emissions }\end{array}$ & Connected Vehicles & $\begin{array}{l}\text { Eco-Approach and Departure at } \\
\text { Signalized Intersections }\end{array}$ \\
\hline Pittsburgh & PA & Pedestrian / Bicyclist Safety & $\begin{array}{l}\text { Intelligent, Sensor-based } \\
\text { Infrastructure }\end{array}$ & Pedestrian Detectors (intersections) \\
\hline Pittsburgh & PA & $\begin{array}{l}\text { Accessibility for People with } \\
\text { Disabilities and the Elderly }\end{array}$ & Smart Land Use & ADA Upgrades at Intersections \\
\hline Pittsburgh & PA & Delays at Intersections & Connected Vehicles & Adaptive Signal System \\
\hline Pittsburgh & PA & $\begin{array}{l}\text { Unpredictable / Unreliable Transit } \\
\text { Service }\end{array}$ & Connected Vehicles & Transit Signal Priority \\
\hline Portland & OR & Delays at Intersections & Connected Vehicles & MMITSS / I-Sig \\
\hline Portland & OR & $\begin{array}{l}\text { Poor Air Quality / Harmful Vehicle } \\
\text { Emissions }\end{array}$ & Connected Vehicles & $\begin{array}{l}\text { Eco-Approach and Departure at } \\
\text { Signalized Intersections }\end{array}$ \\
\hline Portland & OR & Freight Delays / Congestion & Connected Vehicles & Freight Signal Priority \\
\hline Portland & OR & Freight Delays / Congestion & Urban Delivery and Logistics & Freight Signal Priority \\
\hline
\end{tabular}




\begin{tabular}{|c|c|c|c|c|}
\hline City & State & Challenge & Vision Element & Strategy \\
\hline Portland & OR & Pedestrian / Bicyclist Safety & $\begin{array}{l}\text { Intelligent, Sensor-based } \\
\text { Infrastructure }\end{array}$ & Pedestrian Detectors (intersections) \\
\hline Portland & OR & Red Light Violations & Connected Vehicles & Red Light Warning Violation \\
\hline Portland & OR & $\begin{array}{l}\text { Unpredictable / Unreliable Transit } \\
\text { Service }\end{array}$ & Connected Vehicles & Transit Signal Priority \\
\hline $\begin{array}{l}\text { San } \\
\text { Francisco }\end{array}$ & CA & Freight Delays / Congestion & Urban Delivery and Logistics & Freight Signal Priority \\
\hline $\begin{array}{l}\text { San } \\
\text { Francisco }\end{array}$ & CA & Freight Delays / Congestion & Connected Vehicles & Freight Signal Priority \\
\hline $\begin{array}{l}\text { San } \\
\text { Francisco }\end{array}$ & $\mathrm{CA}$ & Delays at Intersections & Connected Vehicles & MMITSS / I-Sig \\
\hline $\begin{array}{l}\text { San } \\
\text { Francisco }\end{array}$ & CA & Pedestrian / Bicyclist Safety & $\begin{array}{l}\text { Intelligent, Sensor-based } \\
\text { Infrastructure }\end{array}$ & Pedestrian Detectors (intersections) \\
\hline $\begin{array}{l}\text { San } \\
\text { Francisco }\end{array}$ & CA & $\begin{array}{l}\text { Accessibility for People with } \\
\text { Disabilities and the Elderly }\end{array}$ & $\begin{array}{l}\text { User-Focused Mobility Services and } \\
\text { Choices }\end{array}$ & Apps for People with Disabilities \\
\hline
\end{tabular}

Data Source: US DOT Smart City Challenge (https://data.transportation.gov/Research-and-Statistics/Smart-City-Challenge-Finalists-Project-Proposals/4zfz-amsd/data\#columnmenu) 


\section{Cost of CAV/CV Based Signal Infrastructure}

With respect to OBUs, if automotive OEMs follow the NHTSA provided regulations for OBE and DSRC in terms of CV deployment, it is anticipated that the vehicle side of V2I will begin to be in place as future model year vehicles are purchased. With the average life span of the fleet exceeding 12 years, it will take several years for the percentage of DSRC equipped vehicles to reach significant proportion. With respect to RSUs, there is no regulation or specific guidelines on how state and local transportation agencies to be prepare for the CAV/CV deployment regarding infrastructure planning and investment. The AASHTO Connected Vehicle Deployment Coalition predicts that about 250,000 traffic signal locations will have V2I communication ability and will be ready for CAV/CV based signal application deployment (Wright et al., 2013b) by 2040. It is important to explore and identify the key investment areas in a CAV-dominant transportation system. The local and state transportation agencies need to know the financial aspects of upgrading the signal infrastructure that is required to deploy CAV/CVbased signal control schemes. The following sections provide directions on the cost estimate for CAV/CV signal infrastructure deployment.

\subsection{Cost estimates from AASHTO footprint analysis}

The National Connected Vehicle Field Infrastructure Footprint Analysis(Wright et al., 2014) by the American Association of State Highway and Transportation Officials (AASHTO) provides information to local and state agencies on CAV/CV deployment features and expectations. The US DOT and Transport Canada supported the study ${ }^{18}$ and AASHTO's Connected Vehicle Deployment Coalition-a group formed by representatives from state and local transportation entities - conducted the analysis. The National CV Field Infrastructure Footprint Analysis provides directions to identify the activities and project timelines associated with the CAV/CV deployment footprint, and to better understand the cost elements relevant to the deployment.

\subsubsection{National deployment of signal infrastructure}

The footprint analysis estimated the total number of deployment sites over the next 20-25 years in the US. The numbers are based on several criteria: (a) the number of signalized intersection to have V2I capability to support primary safety and mobility CV/CAV applications, and (b) the critical locations in road network to attain a desired coverage of CV/CAV environment nationwide.

Table 4 Anticipated CAV deployment of Signalized Intersections

\begin{tabular}{|llll|}
\hline Criterion & Objective & $\begin{array}{l}\text { Deployment } \\
\text { Fraction }\end{array}$ & $\begin{array}{l}\text { Number of } \\
\text { Deployment } \\
\text { Sites }\end{array}$ \\
\hline $\begin{array}{l}\text { Deploy only highest volume } \\
\text { signalized intersections }\end{array}$ & $\begin{array}{l}\text { Attain safety by } \\
\text { corresponding to about 50\% } \\
\text { of all intersection crashes }\end{array}$ & $20 \%$ & 62,200 \\
\hline $\begin{array}{l}\text { Deploy half of all signalized } \\
\text { intersections ranked based on } \\
\text { safety and intersection } \\
\text { performance measures }\end{array}$ & $\begin{array}{l}\text { Attain safety and mobility by } \\
\text { corresponding to 80\% of all } \\
\text { intersection crashes }\end{array}$ & 150\%,500 & \\
\hline
\end{tabular}

\footnotetext{
${ }^{18}$ http://www.itscosts.its.dot.gov/ITS/benecost.nsf/SummID/SC2014-00324?OpenDocument\&Query=Home
} 


\begin{tabular}{|llll|}
\hline Criterion & Objective & $\begin{array}{l}\text { Deployment } \\
\text { Fraction }\end{array}$ & $\begin{array}{l}\text { Number of } \\
\text { Deployment } \\
\text { Sites }\end{array}$ \\
\hline $\begin{array}{l}\text { Deploy CAV/CV capability to all } \\
\text { intersections to enable mobility, } \\
\text { safety, and other applications }\end{array}$ & $\begin{array}{l}\text { Attain all CAV/CV } \\
\text { applications at intersection } \\
\text { level }\end{array}$ & About 80\% & 248,800 \\
\hline
\end{tabular}

Source: (Wright et al., 2014)

\subsubsection{Cost estimates for signal infrastructure}

Cost elements for signal infrastructure include installation of DSRC and RSU, support and maintenance, backhaul deployment, and upgrading the existing control devices. Backhaul deployment is the estimated costs for establishing connectivity from connected vehicle infrastructure to back-end servers and TMCs. It is one of the important elements in the context of signal infrastructure deployment. Backhaul costs highly vary across sites and jurisdictions. The AASHTO report estimates that the initial backhaul cost ranges between $\$ 3000$ and $\$ 40,000$ per site. The cost estimation process assumes:

Table 5 Anticipated cost for signal infrastructure deployment (in 2013 US dollars)

\begin{tabular}{|ll|}
\hline Component & Average cost \\
\hline Signal controller upgrade for interfacing with DSRC RSU & $\$ 3200$ \\
\hline Direct DSRC and RSU installation cost per site & $\$ 17600$ \\
\hline To upgrade backhaul to a DSRC RSU site & $\$ 3000-\$ 40000$ \\
\hline Annual operations and maintenance cost for DSRC RSU site & $\$ 3050$ \\
\hline Integration of Existing Backhaul Equipment & $\$ 3,000$ \\
\hline Installation of New Backhaul & $\$ 40,000$ \\
\hline \multicolumn{2}{r}{ Source: AASHTO Footprint Analysis(Wright et al., 2014) } \\
\hline
\end{tabular}

\subsection{CAV/CV deployment cost estimation using CO-PILOT}

The Cost Overview for Planning Ideas and Logical Organization Tool (CO-PILOT) ${ }^{19}$ launched by the US DOT provides a high-level cost estimate for the Connected Vehicle Pilot Deployments. From infrastructure perspective, CO-PILOT will be applicable for CAV deployment as well. First, a user selects the specific application scenario from $56 \mathrm{CAV} / \mathrm{CV}$ applications. Next, the estimated number of building blocks to be deployed in the pilot study is provided. Building-blocks represent system elements including signalized intersections, transit vehicles, pedestrians, and freight terminals. CO-PILOT reports cost estimates for each deployment building block. Cost components for a signalized intersection block include installation and maintenance costs of RSUs and communication technology. CO-PILOT has default costs and required quantities for each component. Users can modify the costs and quantities to create customized pilot deployment scenarios. CO-PILOT applies a simulation-based approach to accommodate uncertainty in the estimated costs.

\subsubsection{Cost of OBE integration}

Based on preliminary information, NHTSA currently estimates that the V2V OBE equipment and supporting communications functions (including a security management system) would cost approximately $\$ 341$ to $\$ 350$ per vehicle in 2020 . These costs would also include an additional $\$ 9$ to $\$ 18$

${ }^{19}$ https://co-pilot.noblis.org/CVP CET/ 
per year ${ }^{20}$ in fuel costs due to added vehicle weight from the V2V system. This does not include costs for after market integration of safety devices into vehicles for signal control and safety applications.

${ }^{20}$ https://www.its.dot.gov/cv basics/cv basics 20qs.htm 


\section{Concluding Remarks and Future Directions}

This section provides a summary of our synthesis study and identifies the potential challenges and opportunities associated with CV/CAV based signal control deployment in terms of signal settings and infrastructure needs. In addition, future research directions accounting for CAV/CV environment and a vision of integrated data-driven signal control systems are provided.

\subsection{Challenges with CV/CAV based signal control}

Our study identifes five major challenges with signal control deployment in a connected and automated transportation system: (a) effect of market share, (b) investment for the roadside infrastructure, (c) developing and enforcing regulation pertaining to CAV/CV based intersection management, (d) fault tolerance and resistance to cyber-attackes, and (e) traffic flow and intersection modeling accounting for $\mathrm{CV} / \mathrm{CAV}$ environment in simulation tools.

\subsubsection{Impact of CV/CAV market share on performance of signal control applications}

Market adoption is a major factor to determine the impact of CAVs on traffic flow and overall energy from transportation sector. It is critical to find the rate at which CAVs will be adopted by the users and the resulting mix of CAVs and human driven vehicles. It is unknown when CAVs will be commercially available for the users. This depends on the strategic business plans of the automotive OEMs. If DSRC is mandated, the CV portion of CAVs can be accurately modeled based on fleet turnover. Successful implementation of traffic signal applications in a CV/CAV environment highly depends on the level of market penetration. Recent studies suggest that the market share needs to $20 \%$ or more to realize benefits in terms of delay reduction and maximizing throughputs (Day and Bullock, 2016).

Table 6 Impact of market share on performance of CAV/CV based signal control algorithms

\begin{tabular}{|c|c|c|}
\hline Study & Control algorithm type & Impact of market share \\
\hline $\begin{array}{l}\text { (Goodall et al., } \\
\text { 2013) }\end{array}$ & $\begin{array}{l}\text { Demand responsive, } \\
\text { distributed, and uses rolling } \\
\text { horizon optimization of } 15 \mathrm{~s} \\
\text { look-ahead future. Fully } \\
\text { adaptive acyclic signal timing } \\
\text { plan }\end{array}$ & $\begin{array}{l}\text { Most benefits are realized with } 50 \% \text { or higher } \\
\text { share of } C V s \text {, higher performance with } \\
\text { unexpected demand. }\end{array}$ \\
\hline $\begin{array}{l}\text { (He et al., 2014), } \\
\text { (He et al., 2012) }\end{array}$ & $\begin{array}{l}\text { Multi-modal signal control } \\
\text { for arterials }\end{array}$ & Test case only uses $100 \%$ market share \\
\hline $\begin{array}{l}\text { (Priemer and } \\
\text { Friedrich, 2009) }\end{array}$ & $\begin{array}{l}\text { Decentralized adaptive } \\
\text { control }\end{array}$ & $\begin{array}{l}\text { Tested with } 100 \%, 50 \%, 33 \%, 25 \%, 20 \%, 17 \% \text {, } \\
14 \%, 12 \% \text {, and } 10 \% \text { of penetration rate. } \\
\text { Compared with optimized signal plan by TRANSYT- } \\
7 F \text {; low penetration rate the performance was not } \\
\text { improved much; best performance when market } \\
\text { rate is greater than } 33 \% \text {, around } 20 \% \text { the } \\
\text { performance were almost the same; }\end{array}$ \\
\hline $\begin{array}{l}\text { (Feng et al., } \\
2015 \text { ) }\end{array}$ & Real-time adaptive control & $\begin{array}{l}\text { Four market share scenarios were tested: } 25 \% \text {, } \\
50 \%, 75 \% \text {, and } 100 \% \text {. Performance improvements } \\
\text { of the proposed algorithm compared to actuated } \\
\text { control were found when the penetration rate is } \\
\text { equal to or greater than } 50 \% \text { in almost all cases. }\end{array}$ \\
\hline
\end{tabular}




\begin{tabular}{|c|c|c|}
\hline Study & Control algorithm type & Impact of market share \\
\hline $\begin{array}{l}\text { (Ilgin Guler et al., } \\
\text { 2014b) }\end{array}$ & $\begin{array}{l}\text { Autonomous intersection } \\
\text { control }\end{array}$ & $\begin{array}{l}\text { From } 0 \% \text { to } 60 \% \text { market share of CAVs, } \\
\text { experiments show significant reduction of delays } \\
\text { at signalized intersections. The improvement rate } \\
\text { becomes marginal with market share exceeding } \\
60 \% \text {. }\end{array}$ \\
\hline (Lee et al., 2013) & $\begin{array}{l}\text { Real-time control using CV } \\
\text { technology }\end{array}$ & $\begin{array}{l}\text { Improvement requires } 30 \% \text { market share of CV } \\
\text { equipped vehicles. Tested several market shares } \\
\text { from } 10 \% \text { to } 100 \%\end{array}$ \\
\hline $\begin{array}{l}\text { (Goodall et al., } \\
\text { 2014) }\end{array}$ & $\begin{array}{l}\text { Real-time control with } \\
\text { consideration of unequipped } \\
\text { vehicles }\end{array}$ & $\begin{array}{l}\text { Improvements are observed at } 10 \%-25 \% \text { of } \\
\text { market share. }\end{array}$ \\
\hline $\begin{array}{l}\text { (Argote- } \\
\text { Cabañero et al., } \\
\text { 2015) }\end{array}$ & $\begin{array}{l}\text { Estimation of performance } \\
\text { of an arterial at different } \\
\text { market share }\end{array}$ & $\begin{array}{l}\text { Findings indicate that it is possible to predict the } \\
\text { critical market share for most MOEs and traffic } \\
\text { conditions within } 1 \% \text {. }\end{array}$ \\
\hline
\end{tabular}

\subsubsection{Investment for Road Side Units and Communication Backhaul}

The impact of CV/CAV market share can only be leveraged by the installation of road side units in the network. Installing a robust and reliable RSU network insures that the required communication is in place for the signal controller to make the optimal signal timing decisions. Most pilot studies have used DSRC based RSUs in recent years. In the alternative future, $5 \mathrm{G}$ cellular networks may become dominant. If so, the cellular corporations will play a larger role in terms of the use of existing infrastructure for $\mathrm{CV} / \mathrm{CAV}$ based applications, and investment for new infrastructure as the market penetration of CV/CAVs grows.

\subsubsection{Developing and enforcing new regulations for CAVs}

States and local authorities are responsible for emergency response and management (U.S. Department of Transportation, 2016). has Appropriate response to incidents involving CAVs has been identified as one of the current gaps in regulations with respect to the transition from human-driven vehicles equipped with automated safety technologies to fully automated vehicles. CAVs can be involved in traffic crashes, particularly during the period of transition from traditional vehicles to highly automated vehicles. The emergency responders need to be trained for cases specific to the CAVs. Some hazards include remote ignition, silent operation, and abrupt changes in the voltage (in the case of electric vehicles) ${ }^{21}$. The first responders including the police officers, firefighters, medical responders, and the tow service crews. These emergency personnel should have proper training and awareness regarding CAV technology and possible new hazards. According to the federal automated highway policy, the CAVs within the $O D D^{22}$ are required to adapt with various unexpected conditions including re-routing of traffic by police, obeying directions of construction workers, and temporary work zone.

\footnotetext{
${ }^{21}$ http://www.denverpost.com/2017/03/28/uber-self-driving-car-crash-in-arizona-comes-amid-debate-about-regulations/

22 The ODD (Operational Design Domain) provides a description of the specific operating domain(s) in which an automated function or system is designed to operate properly, including but not limited to roadway types, speed range, environmental conditions (weather, daytime/nighttime, etc.), and other domain constraints
} 


\subsubsection{Fault tolerance and resistance to cyber attacks}

CV/CAV environment requires a highly reliable onboard computing and communication and the system needs to be made fault tolerant in case unexpected fault occurs in the system. In this regards, concepts such as collaborative fault tolerant control at vehicle level should therefore be used so that if one CAV has a fault other CAVs can control their movements in a fault tolerant way (Ren et al., 2015) to ensure a safe movement. In addition, cyber security is another important aspect in CV/CAV environment. It is important to secure privacy of the users and secured data exchange CV/CAV environment. The CAVs are supercomputers and if compromised can cause significant damage at a large scale. Under the NCHRP program, a primer on cyber security (Consulting, 2015) for surface transportation has recently published. The aim is to provide transportation agencies with cybersecurity concepts, guidelines, fundamental strategic, management and planning information associated with cybersecurity and its applicability in CV/CAV environment.

\subsubsection{Traffic flow and intersection modeling}

Network level optimization of a signal control system requires a reliable and real-time traffic flow prediction system. In this context, CAV/CV environment will provide a potential solution in the future due to their enhanced communication capabilities with signal infrastructure by providing location, trajectory, and type of vehicles on the system through BSMs. Also from a control systems perspective, the observability of key system parameters and the controllability of system dynamics are both evolving quickly.

\section{Observability}

- Within existing signal control systems, be it fixed time, actuated or adaptive, knowledge of key system parameters such as queue length and demand are based on derivations from presence detectors at either the stop bar or on approach. With the CV/CAVs technology, the trajectory of vehicles on approach and departure for a portion of the traffic stream become available as critical inputs.

- Traffic assessment technologies like re-identification data are beginning to leverage sensor-free approaches quality assessment, similar in nature to CV/CAVs based data from OBU to RSUs, though not in real-time for signal control. However, the performance approach based on statistical distributions of travel time provides the long term feedback on performance that has traditionally been lacking, as well as provides a basis for control approaches.

- Although CV/CAVs will provide enhanced data from equipped vehicles allowing for new optimization schemes, full observability may require enhanced infrastructure sensors for reliability and redundancy. This is particularly true with respect to detecting the absence of vehicles or pedestrians with high-confidence needed to change any safety-critical signal operations related to intersection clearance.

\section{Controllability}

- Existing signal systems control signal phase and timely (SPaT) only, with no ability to directly influence or control individual or group vehicle trajectories (beyond that of reaction to the signal lights).

- CV/CAVs technology increases the available control surface to include vehicle trajectory as well as the signals, altering vehicle speed to allow for increased performance. 


\subsection{Opportunities with CAV/CV based signal control}

Transportation agencies across the U.S. are engaging in new approaches to signal control and there is now a wide variety of institutions and related resources available and now being developed to improve traffic signal management and operations.

a) National Transportation Operations Coalition (NTOC): an online community forums and traffic signal library. https://ntoctsl.groupsite.com

b) Federal Highway Administration: Arterial Management Program (ops.fhwa.dot.gov/ arterial_mgmt/index.htm) and the Office of Safety Intersection Program Intersection Safety Program (http://safety.fhwa.dot.gov/intersection/)

c) American Association of State Highway and Transportation Officials (www.transportation.org) (e.g. subcommittees on systems operation and management; and traffic engineering (see their Manual on Uniform Traffic Control Devices))

d) Institute of Transportation Engineers (ww.ite.org)

e) International Municipal Signal Association (www.imsasafety.org)

f) Transportation Research Board (www.trb.org)

The unique role DOE can play in exploring opportunities with CAV/CV based signal control is to continue to analyze the components of traffic signal operations to address energy-inefficient shortcomings, and provide scenarios for increasing mobility and the energy efficiency of urban travel through signal control and optimization. Examples of high opportunity areas are described next, with future research engaging the workforce in using next-generation performance assessment, management, and optimization approaches.

\subsubsection{Detector free signal control algorithm}

The existing detection capabilities mostly offer point data with fixed locations at a coarse temporal resolution using point detection systems (Federal Highway Administration, 2006). The fully adaptive control schemes will have the ability to adjust automatically to real-time traffic demand, and this gets rid of the need for manual retiming accounting for manual and daily traffic variation. CAV environment offers a detector free option to optimize traffic signal. The CAVs will act as mobile detectors in the system and exchange data with the signal controllers that can be used to develop control schemes (Day and Bullock, 2016; Liu, 2016).

Detector free performance assessment based on vehicle probe data provided by traffic industry is increasing visibility into existing signal control systems. HRCD, re-identification data, and travel time data derived from probe vehicle traffic data sources are beginning to provide system wide observability similar to that anticipate from CV/CAVs. Though not anticipated for real-time control input, the proliferation of these approaches provides significant improvement to established signal infrastructure, as well points toward statistical control methodologies for real-time control.

\subsubsection{Dynamic intersection performance management}

CAVs can be integrated with a central database and the data can be used for performance management of the signalized intersection at network level (Goodall et al., 2013). This offers an integrated system of signalized intersection monitoring and maintenance in real time. Further, the data-driven system can be 
coupled with autonomous intersection management system. If CAVs have powerful onboard computing power, we may not need traffic signal systems at all in road junctions as CAVs can optimize their own movements via communicating with other CAVs in the area and can thus has the ability to automatically pass through road junctions effectively.

\subsubsection{Signal control optimization with energy and emissions objective}

Only a few works exist focusing on the energy minimization objectives in signal control schemes. Most of these studies evaluate the energy and emissions impact (Aziz et al., 2013; Kwak et al., 2012; Li et al., 2011; Rakha et al., 2000). In CV/CAV environment the vehicles with different powertrain and fuel mix can send information to the controllers for energy minimizing control schemes. At the same time, signal control with carbon footprint minimization can be a candidate to build active transportation - walk and bicyclist-friendly transportation networks.

\subsubsection{Air quality monitoring system using CAVs-Signal networks}

With CAVs running in the city and communicating the signal controllers, it is possible to develop an air quality surveillance system. The CAVs can measure the emissions level and then send to the controllers. Afterward, the controllers will share the data with a centralized monitoring and management system.

As a mechanism to achieve these objectives, transportation agencies can further establish or expand traffic monitoring and signal data collection plans and programs. These efforts could help to update signal timing and management programs for anticipating increased used of CVs and CAVs, starting with mixed flow with conventional vehicles and CAVs operating side-by-side. Remaining questions include:

- How quickly will signal infrastructure change in the next 10 to 20 years?

- How will these transitions change energy usage?

- What are potential safety, mobility, and equity considerations (for different modes)?

- How might signal infrastructure play a role in helping to curb or reduce energy usage in the age of increased connectivity and automation?

- Will transportation agencies be held responsible when an accident occurs with an automated vehicle behaving differently due to 'perhaps initially faulty' signal priority systems established?

- What will be the levels of consumer engagement/acceptance of new signal control schemes?

- What is driving the push towards changes in signal infrastructure controls and optimization?

These questions and others will be critical to research and practice roadmaps that can move state-ofthe-art forward, for shaping future advanced transportation technologies and infrastructure systems. We must consider the trajectories of the technological advancement in planning process and investment decisions of signal infrastructure-transportation infrastructure in general. A careful consideration is necessary on the advancement in the vehicle technologies, communication capabilities and infrastructure, and disruptive transportation service such as the transportation network companies, and overall adaptation of the new service and technologies by the users of the transportation system. 


\section{REFERENCES}

Argote-Cabañero, J., Christofa, E., Skabardonis, A., 2015. Connected vehicle penetration rate for estimation of arterial measures of effectiveness. Transp. Res. Part C Emerg. Technol. 60, 298-312. doi:10.1016/j.trc.2015.08.013

Aziz, H.M.A., Zhu, F., Ukkusuri, S. V, 2013. Reinforcement Learning-Based Signal Control Using R-Markov Average Reward Technique (RMART) Accounting for Neighborhood Congestion Information Sharing. Transp. Res. Board 92nd Annu. Meet. 13-3227.

Bazzan, A.L.C., de Oliveira, D., da Silva, B.C., 2010. Learning in groups of traffic signals. Eng. Appl. Artif. Intell. 23, 560-568.

Bezzina, D., Sayer, J., 2015. Safety pilot model deployment: Test conductor team report. Rep. No. DOT HS 812, 171.

Carlino, D., Boyles, S.D., Stone, P., 2013. Auction-based autonomous intersection management. IEEE Conf. Intell. Transp. Syst. Proceedings, ITSC 529-534. doi:10.1109/ITSC.2013.6728285

Consulting, W.M., 2015. Protection of Transportation Infrastructure from Cyber Attacks: A Primer, National Cooperative Highway Research Program. National Academies Press. doi:10.17226/23516

Day, C.M., Bullock, D.M., 2016. Detector-Free Signal Offset Optimization with Limited Connected Vehicle Market Penetration. Transp. Res. Rec. J. Transp. Res. Board 2558, 54-65. doi:10.3141/2558-06

Dresner, K., Stone, P., 2008. A multiagent approach to autonomous intersection management. J. Artif. Intell. Res. 31, 591-656. doi:10.1613/jair.2502

Fajardo, D., Au, T.-C., Waller, S.T., Stone, P., Yang, D., 2011. Automated intersection control: Performance of future innovation versus current traffic signal control. Transp. Res. Rec. 223-232. doi:10.3141/2259-21

Federal Highway Administration, 2006. Traffic Detector Handbook, Vol. 2. doi:FHWA-HRT-06-108 October

Feng, Y., Head, K.L., Khoshmagham, S., Zamanipour, M., 2015. A real-time adaptive signal control in a connected vehicle environment. Transp. Res. Part C Emerg. Technol. 55, 460-473. doi:10.1016/j.trc.2015.01.007

Goodall, N., Smith, B., Park, B., 2013. Traffic Signal Control with Connected Vehicles. Transp. Res. Rec. ... 2381, 65-72. doi:10.3141/2381-08

Goodall, N.J., Park, B. (Brian), Smith, B.L., 2014. Microscopic Estimation of Arterial Vehicle Positions in a Low-Penetration-Rate Connected Vehicle Environment. J. Transp. Eng. 140, 4014047. doi:10.1061/(ASCE)TE.1943-5436.0000716

Gordon, R., Tighe, W., 2005. Traffic Control Systems Handbook, Federal Highway Administration. 
Hainen, A.M., Day, C.M., Mackey, J., Taylor, M., Luker, M., 2015. High - Resolution Controller Data Performance Measures for Optimizing Diverging Diamond Interchanges and Outcome Assessment with Drone Video. Transp. Res. Rec. J. Transp. Res. Board 2487, 31-43. doi:10.3141/2487-03

He, Q., Head, K.L., Ding, J., 2012. PAMSCOD: Platoon-based arterial multi-modal signal control with online data. Transp. Res. Part C Emerg. Technol. 20, 164-184. doi:10.1016/j.trc.2011.05.007

He, Q., Head, K.L., Ding, J., 2014. Multi-modal traffic signal control with priority, signal actuation and coordination. Transp. Res. Part C Emerg. Technol. 46, 65-82. doi:10.1016/j.trc.2014.05.001

Hill, C., 2013. Module 13: Connected Vehicles. ITS ePrimer - U.S. DOT 1-50.

Hill, C.J., Garrett, K.J., 2011. AASHTO Connected Vehicle Infrastructure Deployment Analysis.

Hu, J., Park, B.B., Lee, Y.-J., 2015. Coordinated transit signal priority supporting transit progression under Connected Vehicle Technology. Transp. Res. Part C Emerg. Technol. 1, 393-408. doi:10.1016/j.trc.2014.12.005

Ilgin Guler, S., Menendez, M., Meier, L., 2014a. Using connected vehicle technology to improve the efficiency of intersections. Transp. Res. Part C Emerg. Technol. 46, 121-131. doi:10.1016/j.trc.2014.05.008

Ilgin Guler, S., Menendez, M., Meier, L., 2014b. Using connected vehicle technology to improve the efficiency of intersections. Transp. Res. Part C Emerg. Technol. 46, 121-131. doi:10.1016/j.trc.2014.05.008

Jacob, C., Abdulhai, B., 2006. Automated Adaptive Traffic Corridor Control Using Reinforcement Learning: Approach and Case Studies. Transp. Res. Rec. J. Transp. Res. Board 1959, 1-8.

Krohn, D., Rymarcsuk, L., Mathew, J., Day, C., Li, H., Patel, A., Farley, D., Bullock, D., 2017. Outcome Assessment using Connected Vehicle Data to Justify Signal Investments to Decision Makers. Transp. Res. Board 96th Annu. Meet. Annu. Meet. Pap. no. 17-00314 1-21.

Kwak, J., Park, B., Lee, J., 2012. Evaluating the impacts of urban corridor traffic signal optimization on vehicle emissions and fuel consumption. Transp. Plan. Technol. 35, 145-160.

Lee, J., Park, B. (Brian), Yun, I., 2013. Cumulative Travel-Time Responsive Real-Time Intersection Control Algorithm in the Connected Vehicle Environment. J. Transp. Eng. 139, 1020-1029. doi:10.1061/(ASCE)TE.1943-5436.0000587

Levin, M.W., Fritz, H., Boyles, S.D., 2016. On Optimizing Reservation-Based Intersection Controls. IEEE Trans. Intell. Transp. Syst. 18, 505-515. doi:10.1109/TITS.2016.2574948

Li, J.-Q., Wu, G., Zou, N., 2011. Investigation of the impacts of signal timing on vehicle emissions at an isolated intersection. Transp. Res. Part D Transp. Environ. 16, 409-414.

Li, Z. a, Chitturi, M.V. a, Zheng, D. a, Bill, A.R. a, Noyce, D. a. a, 2013. Modeling Reservation-Based Autonomous Intersection Control in VISSIM. Transp. Res. Rec. J. Transp. Res. Board 2381, 81-90. doi:10.3141/2381-10 
Liu, H., 2016. Next Generation Traffic Control with Connected and Automated Vehicles, in: Automated Vehicle Symposium 2016. San Francisso, CA.

Mixon, L.T., Garrett, J.K., Krueger, B.C., 2012. Vehicle Infrastructure Integration (VII) Data Use Analysis and Processing: Project summary report. Mix. Michigan Inc. Michigan D.

Priemer, C., Friedrich, B., 2009. A decentralized adaptive traffic signal control using V2I communication data. 2009 12th Int. IEEE Conf. Intell. Transp. Syst. 765-770. doi:10.1109/ITSC.2009.5309870

Qureshi, K.N., Abdullah, A.H., 2013. A Survey on Intelligent Transportation Systems. Middle-East J. Sci. Res. 15, 629-642. doi:10.5829/idosi.mejsr.2013.15.5.11215

Rajasri, K., Rahul, S., Gupta, P., 2015. Survey on Adaptive Traffic Signal Control 3, 98-104.

Rakha, H., Van Aerde, M., Ahn, K., Trani, A., 2000. Requirements for Evaluating Traffic Signal Control Impacts on Energy and Emissions Based on Instantaneous Speed and Acceleration Measurements. Transp. Res. Rec. J. Transp. Res. Board 1738, 56-67.

Ren, Y., Wang, A., Wang, H., 2015. Fault Diagnosis and Tolerant Control for Discrete Stochastic Distribution Collaborative Control Systems. IEEE Trans. Syst. Man, Cybern. Syst. 45, 462-471. doi:10.1109/TSMC.2014.2358635

Skabardonis, A., Shladover, S., Zhang, W., Others, 2013. Advanced Traffic Signal Control Algorithms. Calif. PATH Progr. UCB-ITS-PR.

Stevanovic, A., 2010. Adaptive Traffic Control Systems: Domestic and Foreign State of Practice, Transportation. National Academies Press. doi:10.17226/14364

Stevanovic, a, 2010. Adaptive traffic control systems: domestic and foreign state of practice, Transportation Research Board of the National Academies.

Talukder, M.A.S., Hanien, A., Remias, S., Bullock, D.M., 2017. ROUTE-BASED MOBILITY PERFORMANCE METRICS USING PROBE VEHICLE TRAVEL 2 TIMES. Transp. Res. Board 96 Annu. Meet. Washington.

Transportation, I., Its, S., Program, J., Jpo, O., 2014. Intelligent Transportation Systems (ITS) Strategic Plan 2015-2019.

TTI, 2012. Synthesis Study of Texas Signal Control Systems.

U.S. Department of Transportation, 2016. Federal Automated Vehicles Policy. doi:12507-091216-v9

US DOT, 2016. Smart City Challenge: Addressing the Challenges of Today and Tomorrow.

Wright, J., Garrett, J.K., Hill, C.J., Krueger, G.D., Evans, J.H., Andrews, S., Wilson, C.K., Rajbhandari, R., Burkhard, B., 2013a. National Connected Vehicle Field Infrastructure Footprint Analysis. US DOT RITA Joint, 159. doi:DTFH61-11-D-00008

Wright, J., Garrett, J.K., Hill, C.J., Krueger, G.D., Evans, J.H., Andrews, S., Wilson, C.K., Rajbhandari, R., Burkhard, B., 2014. National Connected Vehicle Field Infrastructure Footprint Analysis-Final Report. 
Fed. Highw. Adm. ITS-JPO, 159. doi:DTFH61-11-D-00008

Wright, J., Hill, C.J., Garrett, J.K., Rajbhandari, R., 2013b. National Connected Vehicle Field Infrastructure Footprint Analysis-Deployment Scenarios. AASHTO RITA Joint, 159. doi:DTFH61-11-D-00008

Young, S.E., Sharifi, E., Day, C.M., Bullock, D.M., 2016. Visualizations of Travel Time Performance based on Vehicle Re-identification Data. Transp. Res. Board 96th Annu. Meet. Annu. Meet. Pap. no. 1704936.

Zhang, J., Wang, F.-Y., Wang, K., Lin, W.-H., Xu, X., Chen, C., 2011. Data-Driven Intelligent Transportation Systems: A Survey. IEEE Trans. Intell. Transp. Syst. 12, 1624-1639. doi:10.1109/TITS.2011.2158001

Zhao, D., Member, S., Dai, Y., Zhang, Z., 2012. Computational Intelligence in Urban Traffic Signal Control : A Survey. IEEE Trans. Syst. Man, Cybern. 42, 485-494. doi:10.1109/TSMCC.2011.2161577

Zheng, F., van Zuylen, H.J., Liu, X., Le Vine, S., 2016. Reliability-Based Traffic Signal Control for Urban Arterial Roads. IEEE Trans. Intell. Transp. Syst. 18, 643-655. doi:10.1109/TITS.2016.2582920

Zhu, F., Aziz, H.M.A., Qian, X., Ukkusuri, S. V, 2015. A junction-tree based learning algorithm to optimize network wide traffic control: A coordinated multi-agent framework. Transp. Res. Part C Emerg. Technol. 58, Part C, 487-501. doi:http://dx.doi.org/10.1016/j.trc.2014.12.009

Zhu, F., Aziz, H.M.A., Qian, X., Ukkusuri, S. V, n.d. A Junction-Tree Based Learning Algorithm to Optimize Network Wide Traffic Control : A Coordinated Multi-agent Framework. Transp. Res. Part CEmerging Technol. (in Press.

Zhu, F., Ukkusuri, S. V., 2015. A linear programming formulation for autonomous intersection control within a dynamic traffic assignment and connected vehicle environment. Transp. Res. Part C Emerg. Technol. 1, 363-378. doi:10.1016/j.trc.2015.01.006 